\title{
A revision of dragon millipedes II: the new genus Nagaxytes gen. nov., with the description of three new species (Diplopoda, Polydesmida, Paradoxosomatidae)
}

\author{
Ruttapon SRISONCHAI ${ }^{1}$, Henrik ENGHOFF ${ }^{2, *}$, \\ Natdanai LIKHITRAKARN ${ }^{3,4} \&$ Somsak PANHA ${ }^{4, *}$
}

\author{
${ }^{1}$ Biological Sciences Program, Faculty of Science, Chulalongkorn University, \\ Phaya Thai Road, Patumwan, Bangkok 10330, Thailand. \\ ${ }^{2}$ Natural History Museum of Denmark, University of Copenhagen, Universitetsparken 15, \\ DK-2100 København Ø, Denmark. \\ ${ }^{3}$ Division of Plant Protection, Faculty of Agricultural Production, Maejo University, \\ San Sai, Chiang Mai 50290, Thailand. \\ ${ }^{4}$ Animal Systematics Research Unit, Department of Biology, Faculty of Science, Chulalongkorn \\ University, Phayathai Road, Patumwan, Bangkok 10330, Thailand. \\ *Corresponding authors: Somsak Panha (somsak.pan@chula.ac.th) and Henrik Enghoff \\ (henghoff@snm.ku.dk) \\ 1Email: ruttapon60104@yahoo.com \\ ${ }^{3}$ Email: kongerrrr@hotmail.com

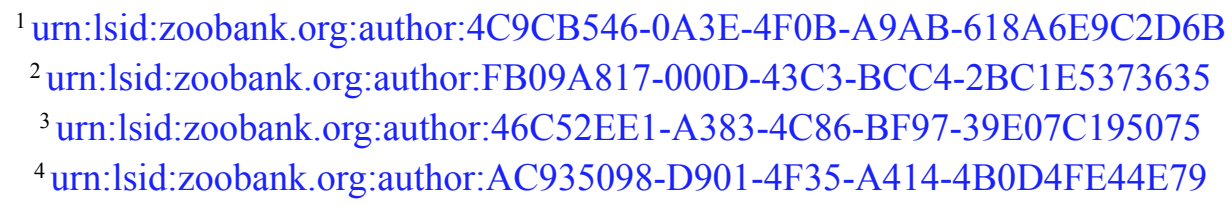

\begin{abstract}
The 'acantherpestes' group of dragon millipedes, formerly placed in the genus Desmoxytes Chamberlin, 1923, is revised and assigned to the new genus Nagaxytes Srisonchai, Enghoff \& Panha gen. nov. Desmoxytes acantherpestes Golovatch \& Enghoff, 1994 is the type species of the new genus and is redescribed as N. acantherpestes (Golovatch \& Enghoff, 1994) gen. et comb. nov. Three new species are described from Thailand: N. erecta Srisonchai, Enghoff \& Panha gen. et sp. nov. and $N$. gracilis Srisonchai, Enghoff \& Panha gen. et sp. nov. from Kanchanaburi Province, and N. spatula Srisonchai, Enghoff \& Panha gen. et sp. nov. from Tak Province. All new species are endemic to western Thailand and all are restricted to limestone habitats. Complete illustrations of external morphological characters, an identification key, and a distribution map are provided.
\end{abstract}

Keywords. Endemic, dragon millipede, new species, taxonomy, Thailand. 
Srisonchai R., Enghoff H., Likhitrakarn N. \& Panha S. 2018. A revision of dragon millipedes II: the new genus Nagaxytes gen. nov., with the description of three new species (Diplopoda, Polydesmida, Paradoxosomatidae). European Journal of Taxonomy 462: 1-44. https://doi.org/10.5852/ejt.2018.462

\section{Introduction}

Srisonchai et al. (2018) subdivided the dragon millipede genus Desmoxytes Chamberlin, 1923, sensu Golovatch \& Enghoff (1994) into five groups based on morphological characters and DNA sequence data; they regarded each of the groups as a separate genus. In the present article, the second in a series of articles about a revision of the dragon millipedes, we revise the 'acantherpestes' group sensu Srisonchai et al. (2018). For this group we erect the new genus Nagaxytes Srisonchai, Enghoff \& Panha gen. nov. to include Desmoxytes acantherpestes Golovatch \& Enghoff, 1994 from western Thailand as well as three new species.

The new genus Nagaxytes gen. nov. is narrowly distributed and restricted to limestone areas. All species are known only from western Thailand: Kanchanaburi, Prachuap Khiri Khan and Tak Provinces.

\section{Material and methods}

\section{Specimen collecting and preservation}

Specimens of Nagaxytes gen. nov. were collected by hand from many localities in the western part of Thailand. The main collectors are staff and students from the Animal Systematics Research Unit, Department of Biology, Faculty of Science, Chulalongkorn University, referred to as 'ASRU members'. Coordinates and elevation were recorded by using Garmin GPSMAP 60 CSx, and were subsequently double-checked with Google Earth.

After collecting and photographing, most specimens were preserved in $70 \%$ ethanol for morphological study and some in $95 \%$ ethanol for molecular analysis (specimens kept in 95\% ethanol at room temperature were later stored at $-20^{\circ} \mathrm{C}$ in a freezer).

\section{Illustrations}

Living specimens were photographed using a Nikon 700D+AFS VR with a $105 \mathrm{~mm}$ lens. Scanning electron microscope images (SEMs) of gonopods were generated with a JEOL JSM-5410 LV. All objects were mounted on aluminium stubs and coated with gold; after imaging the objects were removed from the stubs and kept dry in eppendorf tubes. Drawings were sketched under a stereo microscope and finished using dot-line techniques.

\section{Morphological descriptions}

Specimens were studied for non-gonopod and gonopod characters under a stereo microscope and under SEM. Non-gonopod characters include size, colour, head, antennae, collum, tegument, prozona, metaterga, paraterga, telson, sterna, and legs. We use the morphological terminology according to previously published taxonomic papers (Jeekel 1964, 1980, 2003; Golovatch \& Enghoff 1994; Enghoff et al. 2007; Srisonchai et al. 2016, 2018). Details of gonopod characters are provided in the gonopod terminology section below.

\section{Deposition of holotypes, paratypes and other new specimens}

All holotypes, some paratypes of the new species and new specimens are housed in CUMZ. Some paratypes and some new specimens are housed at NHMUK, NHMW, ZMUC and ZMUM. 


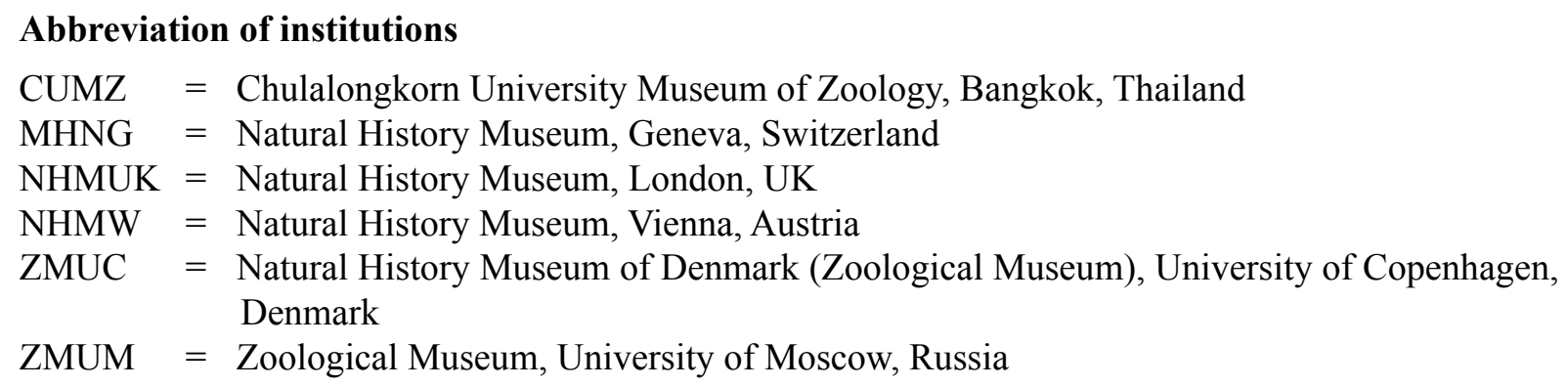

Other abbreviations used in the text

ASRU = Animal Systematics Research Unit, Department of Biology, Faculty of Science, Chulalongkorn University, Bangkok, Thailand

a.s.l. $\quad=$ above sea level

ca. $\quad=$ about, around (circa)

\section{Gonopod terms for the genus Nagaxytes gen. nov., and their abbreviations}

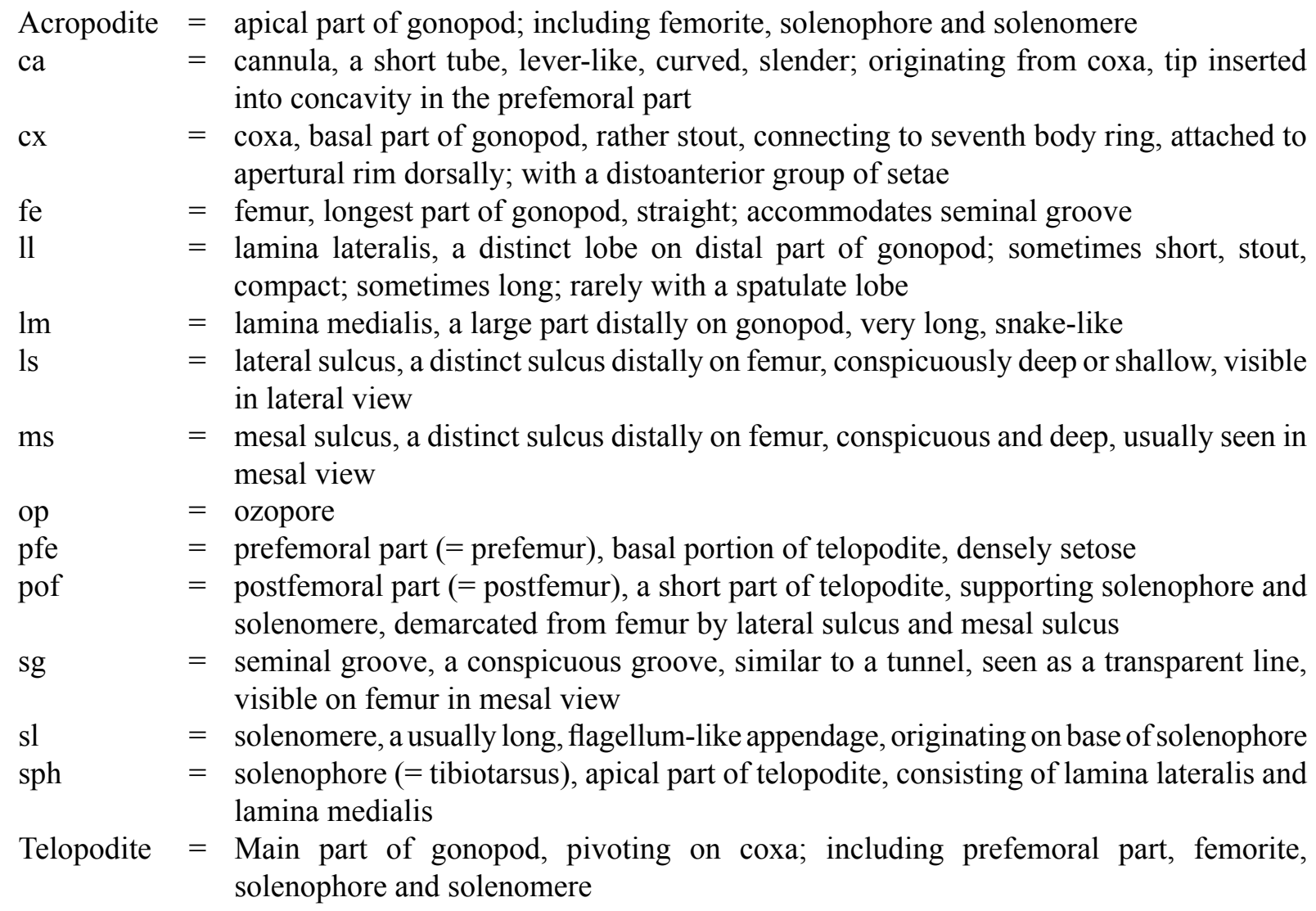

\section{Positional/directional terms in gonopod description}

Traditionally the gonopods are depicted as rotated $90^{\circ}$ up from their in situ position (following the terminology of Srisonchai et al. 2018).

Dorsal $=$ position on the side nearest to the body ring

Ventral $=$ position on the side farthest away from the body ring

Mesal $=$ position on the side nearest to the midline

Lateral $=$ position on the side furthest from the midline 
Dorsad $=$ direction towards the body ring

Ventrad $=$ direction away from the body ring

Mesad $=$ direction towards the midline

Laterad $=$ direction away from the midline

We use 'sub-' as a prefix referring to positions and directions slightly different from the ones given above. For example, 'subdorsal' means a position close to, but not quite on the dorsal side.

\section{Results}

\section{Taxonomy}

Class Diplopoda Blainville-Gervais, 1844

Order Polydesmida Pocock, 1887

Suborder Strongylosomatidea Brölemann, 1916

Family Paradoxosomatidae Daday, 1889

Subfamily Paradoxosomatinae Daday, 1889

Tribe Orthomorphini Brölemann, 1916

Genus Nagaxytes Srisonchai, Enghoff \& Panha gen. nov.

urn:1sid:zoobank.org:act:D3B82632-5FC4-4605-AC19-99EAFEB6A23B

\section{Type species}

Desmoxytes acantherpestes Golovatch \& Enghoff, 1994

\section{Diagnosis}

The genus Nagaxytes gen. nov. is characterized by:

1. Paraterga subspiniform.

2. Metaterga with 2 rows of tubercles/cones/spines (lateral spines of posterior row very long).

3. Male femora 5 and 6 without modification.

4. Postfemoral part of gonopod conspicuous, demarcated from femur by a deep mesal sulcus and a shallow/deep lateral sulcus.

5. Lamina lateralis obviously separated from lamina medialis.

6. Lamina medialis long and curved, apically fringed/hooked.

\section{Etymology}

'Naga' is a Sanskrit and Pali word, relating to a category of snake-like spirits in Buddhist and Hindu mythology, and refers to the snake-like shape of the lamina medialis of the gonopod; '-xytes' ensures harmony with Desmoxytes (and its synonym Pteroxytes Jeekel, 1980).

\section{Included species (4)}

- N. acantherpestes (Golovatch \& Enghoff, 1994) gen. et comb. nov.

- N. erecta Srisonchai, Enghoff \& Panha gen. et sp. nov.

- N. gracilis Srisonchai, Enghoff \& Panha gen. et sp. nov.

- N. spatula Srisonchai, Enghoff \& Panha gen. et sp. nov.

\section{Remarks}

Srisonchai et al. (2018) proposed to subdivide Desmoxytes sensu Golovatch \& Enghoff (1994) into five genera. The 'acantherpestes' group (= Nagaxytes) is well-defined by several distinct morphological 
characters (see diagnosis), especially the distinctive subspiniform paraterga and the very long lamina medialis of the gonopods. Even though the subspiniform paraterga are relatively similar to those of the 'gigas' group, the gonopod details are very different.

\section{General description of Nagaxytes gen. nov.}

The description applies to adult males and females, except for the gonopods or when 'male' is specified (Figs 1-3). The general description of gonopods is based mainly on Nagaxytes gracilis gen. et sp. nov. (Figs 4-5).

Size. Body length 22-34 mm (male) 24-38 mm (female), width ca. 2.0-2.4 mm (male) $2.8-3.4 \mathrm{~mm}$ (female), varies between species, usually female wider and longer than male.

Colour (Figs 1, 11-12, 17, 22). Specimens in life with brown or reddish brown colour or pinkish brown (possibly aposematic colouration). Colour in alcohol: all specimens partly faded to pale whitish brown after one year's preservation in alcohol; specimens kept in darkness faded more slowly.

ANTENNAE (Fig. 2A-B, D). Long and slender, covered by delicate setation, usually reaching backwards to body ring 5-7 (male) and 4-6 (female) when stretched dorsally. Antennomere $3=4>5 \geq 2>6>1>7>8$.

HEAD. Delicately setose; vertex, labrum and genae delicately setose; epicranial suture conspicuous as brown stripe.

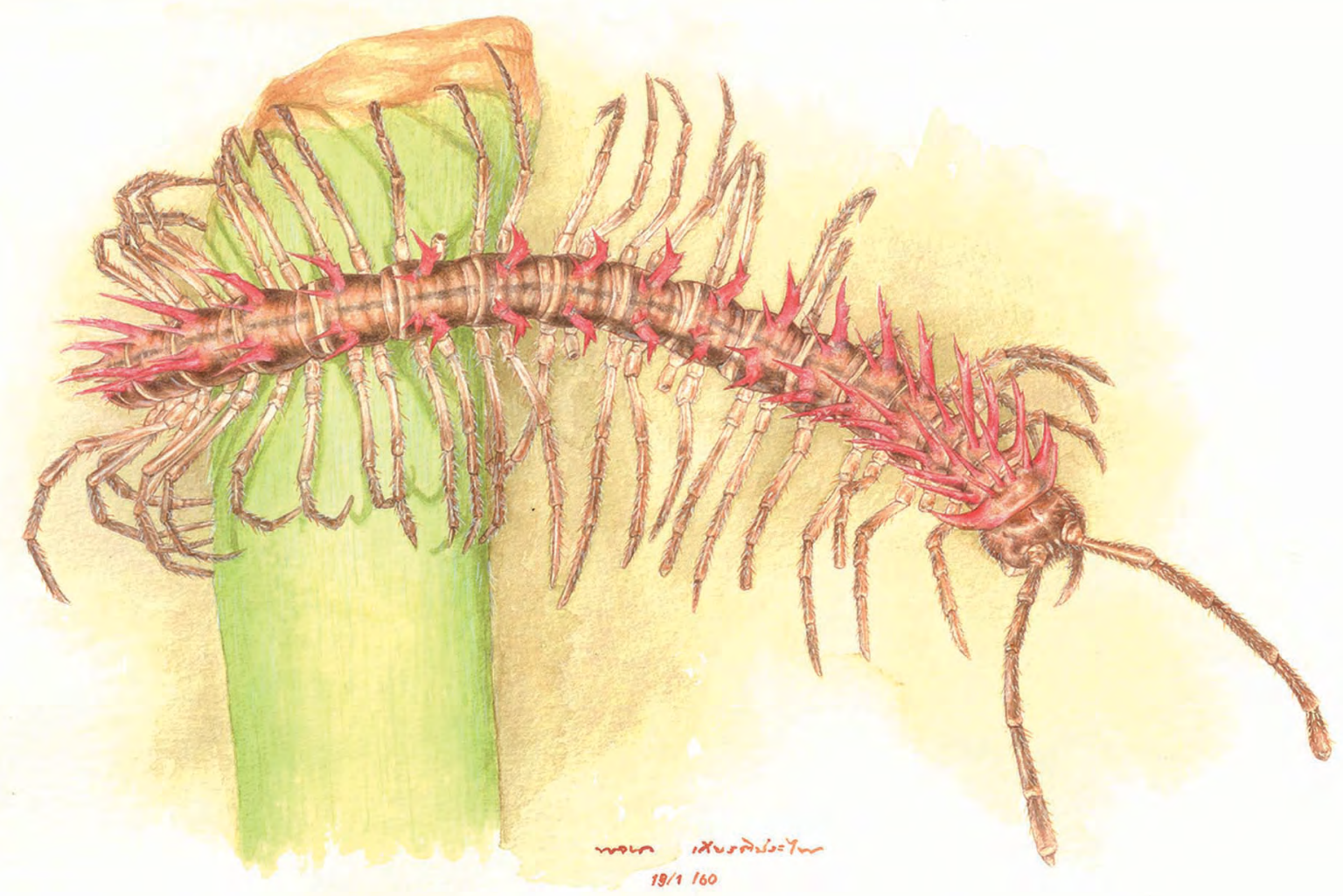

Fig. 1. Nagaxytes gracilis Srisonchai, Enghoff \& Panha gen. et sp. nov., $\widehat{o}$, paratype (CUMZpxDGT00095). Watercolour by R. Srisonchai and P. Kriatpraprai. 


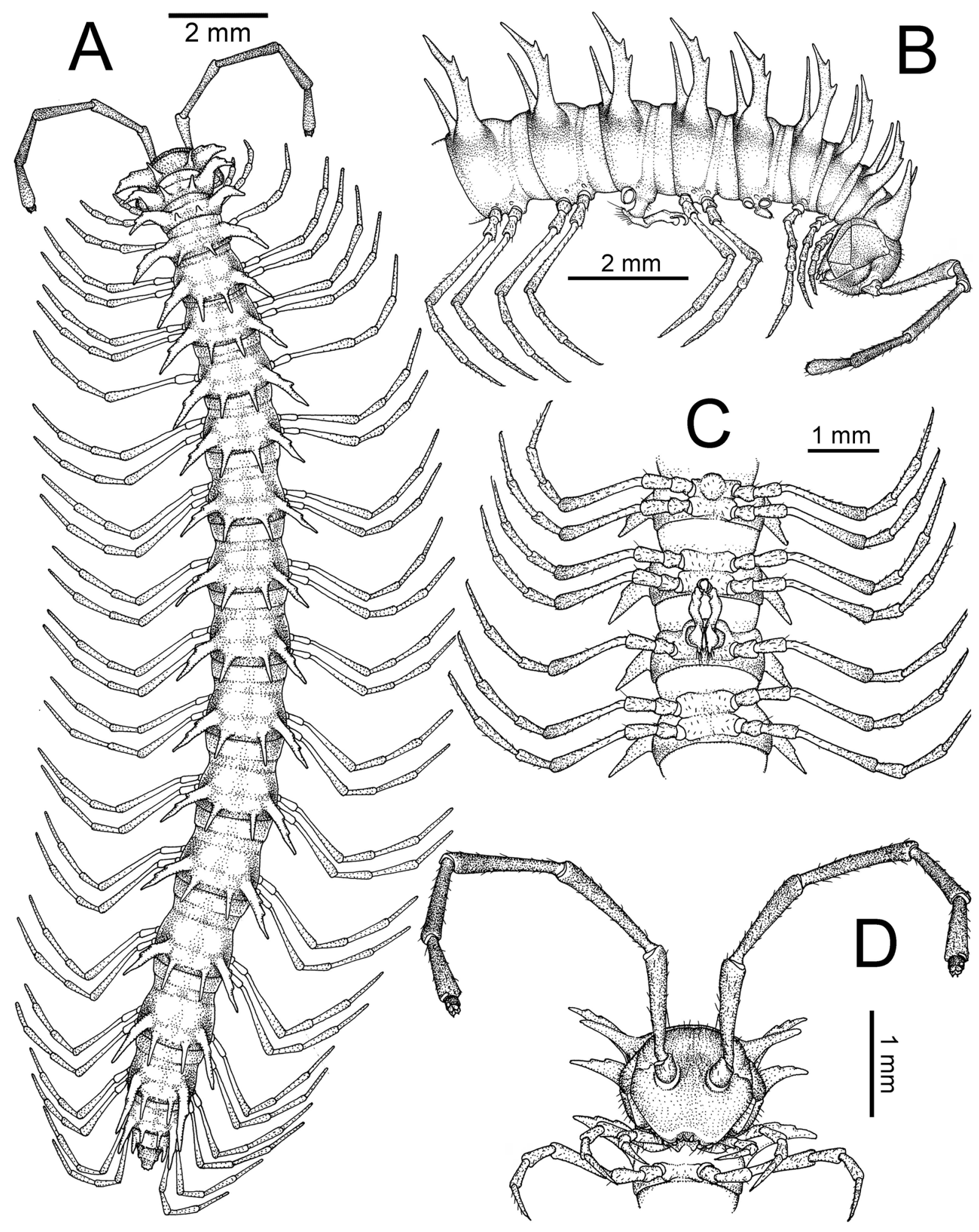

Fig. 2. General body characters of Nagaxytes Srisonchai, Enghoff \& Panha gen. nov. $-N$. acantherpestes (Golovatch \& Enghoff, 1994) gen. et comb. nov., Ô, holotype, Prachuap Khiri Khan Province, Hua Hin District (ZMUC 000101457). A. Entire body. B. Anterior body part. C. Body rings 5-8, showing sternal lobe between coxae 4 and gonopods on ring 7. D. Head and antennae. 


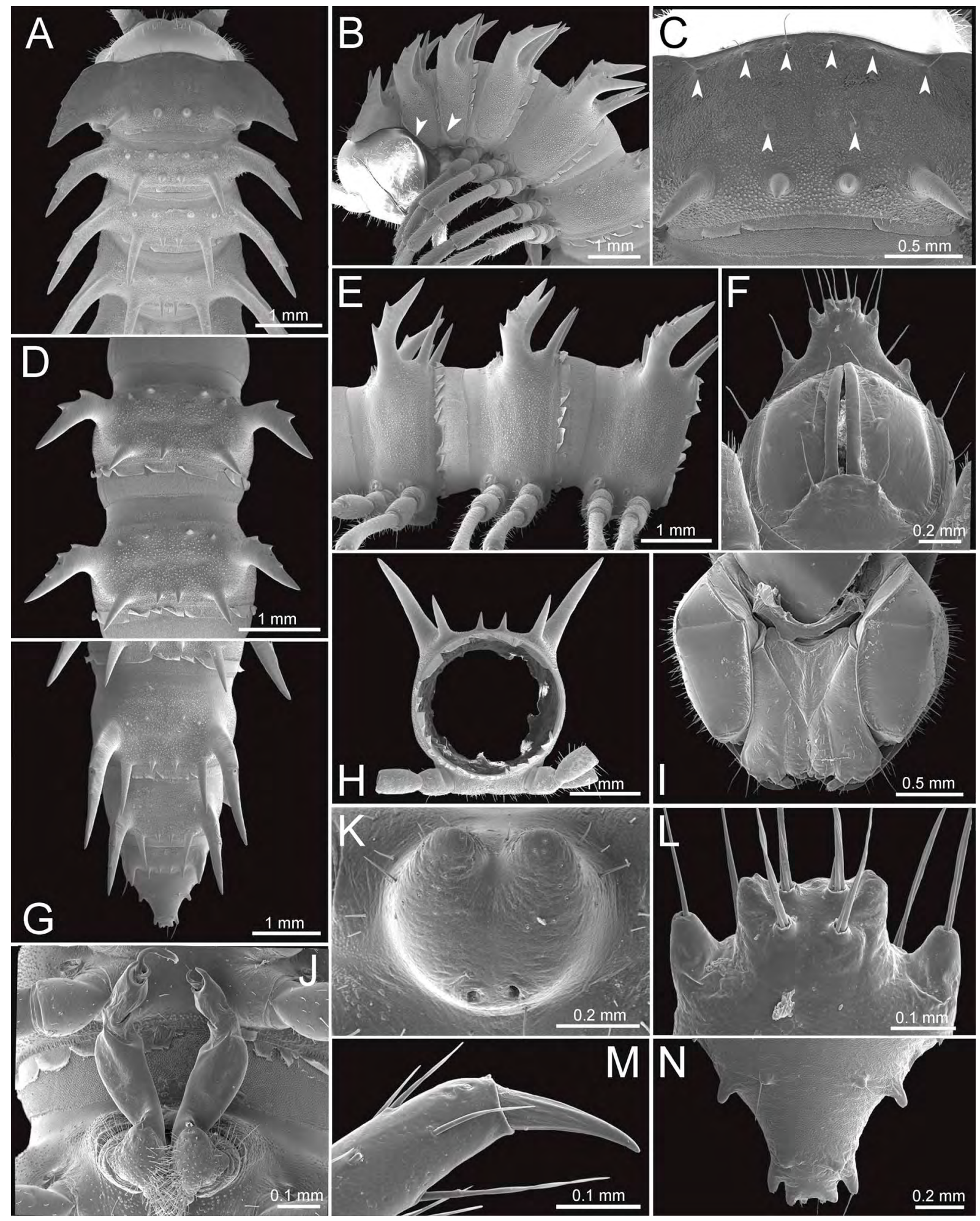

Fig. 3. General body characters of Nagaxytes Srisonchai, Enghoff \& Panha gen. nov. (N. erecta Srisonchai, Enghoff \& Panha gen. et sp. nov., specimen from Prang Ka Sri Temple, Thailand), SEM images. A-B. Anterior body part (arrowheads point to pleurosternal carinae). C. Collum (arrowheads point to the setae/tubercles of the anterior and intermediate rows). D. Body rings 9-10. E. Body rings 8-10. F. Telson. G. Posteriormost rings and telson. H. Body ring 10. I. Mouth parts, ventral view. J. Gonopods in situ. K. Sternal lobe between male coxae 4. L, N. Tip of epiproct. M. Tarsus and claw of leg 13. 
Collum (Fig. 3A, C). With three transverse rows of setae/tubercles and spines; $3+3$ setae/tubercles (anterior row), 1+1 setae/tubercles (intermediate row) and $2+2$ spines (posterior row); lateral spines of posterior row very long. Paraterga of collum wing-like, usually elevated at ca. $25^{\circ}-40^{\circ}$, with two conspicuous notches at lateral margin.

Tegument (Fig. 3A-G). Often dull, sometimes quite shiny; collum, metaterga (except anterior part of metaterga smooth) and surface below paraterga finely microgranulate; prozona finely shagreened; paraterga, sterna and epiproct smooth. Stricture between prozona and metazona wide, usually quite shallow, sometimes quite deep.

Metaterga (Figs 2A, 3A, D, G). With one or two transverse rows of setae/tubercles and spines; usually with $2+2$ setae/tubercles/cones/spines in anterior row and $2+2$ spines in posterior row (sometimes setae/ tubercles/cones/spines in anterior row poorly developed or absent); lateral spines of posterior row longer and larger than mesal ones. Suture (transverse sulcus) on metaterga quite deep, conspicuous on body ring 5-17 in all species. Mid-dorsal (axial) line missing.

Pleurosternal carinae (Fig. 3B). Forming a complete crest on ring 2, smalls ridges on ring 3 and/or 4, missing on remaining body rings.

Paraterga (Fig. 3A-B, D-E, G-H). Subspiniform, long, elevated at ca. $50^{\circ}-70^{\circ}$ (male) or $45^{\circ}-70^{\circ}$ (female), directed caudolaterad on rings $2-17$ or 2-18, directed increasingly caudad on ring 19 or 18-19. Callus and shoulder poorly developed. Anterior margin with two distinct notches; on body rings 9, 10, $12,13,15-18$ a denticle usually present at lateral margin near tip (denticle absent in some rings). Degree of elevation of paraterga in male usually higher than in female. Posterior edge concave; posterior angle pointed and sharp. Ozopore visible in lateral and dorsal views, round, small, somewhat inconspicuous.

Telson (Fig. 3F-G, L, N). Epiproct quite short, often flattened dorsoventrally, tip usually subtruncate, sometimes emarginate; lateral setiferous tubercles conspicuous, digitiform; apical tubercles mostly conspicuous, sometimes inconspicuous; setiferous tubercles beyond lateral setiferous tubercles long, digitiform; epiproct apically with four spinnerets at the corners of a square, not in a depression, anterior pair close to apical tubercles (Fig. 3L). Paraprocts convex. Hypoproct subtriangular or subtrapeziform; caudal margin often subtriangular, sometimes round, with two conspicuous or inconspicuous setiferous tubercles.

Sterna (Figs 2C, 3K). Sparsely setose; cross-impressions somewhat deep, sometimes quite shallow. Sternal lobe between male coxae 4 modified; usually subtrapeziform, sometimes incompletely bilobed, varying between species; tip slightly emarginate, sometimes deeply emarginate or even incompletely bilobed; with two pores seen in posterior view.

Legs (Fig. 2A-C). Very long and slender. Relative lengths of podomeres: femur $>$ tarsus $>$ tibia $>$ prefemur $=$ postfemur $>$ coxa $>$ claw. Male femora 5 and 6 without modification in all species.

Gonopods (Figs 4-5). Coxa longer than prefemoral part, with a distoanterior group of setae. Cannula long or short. Telopodite straight. Prefemoral part usually shorter than femur, sometimes subequal in length to femur. Femur usually long, sometimes quite short. Seminal groove running entirely on mesal surface of femur. Mesal sulcus and lateral sulcus conspicuous. Postfemoral part conspicuous, shorter than femur. Solenophore well-developed: lamina lateralis variously modified; swollen, sometimes long digitiform/lamella-like and projecting, sometimes with spatula-like lobe: lamina medialis longer than lamina lateralis, snake-like, tip curving down. Solenomere relatively long. 


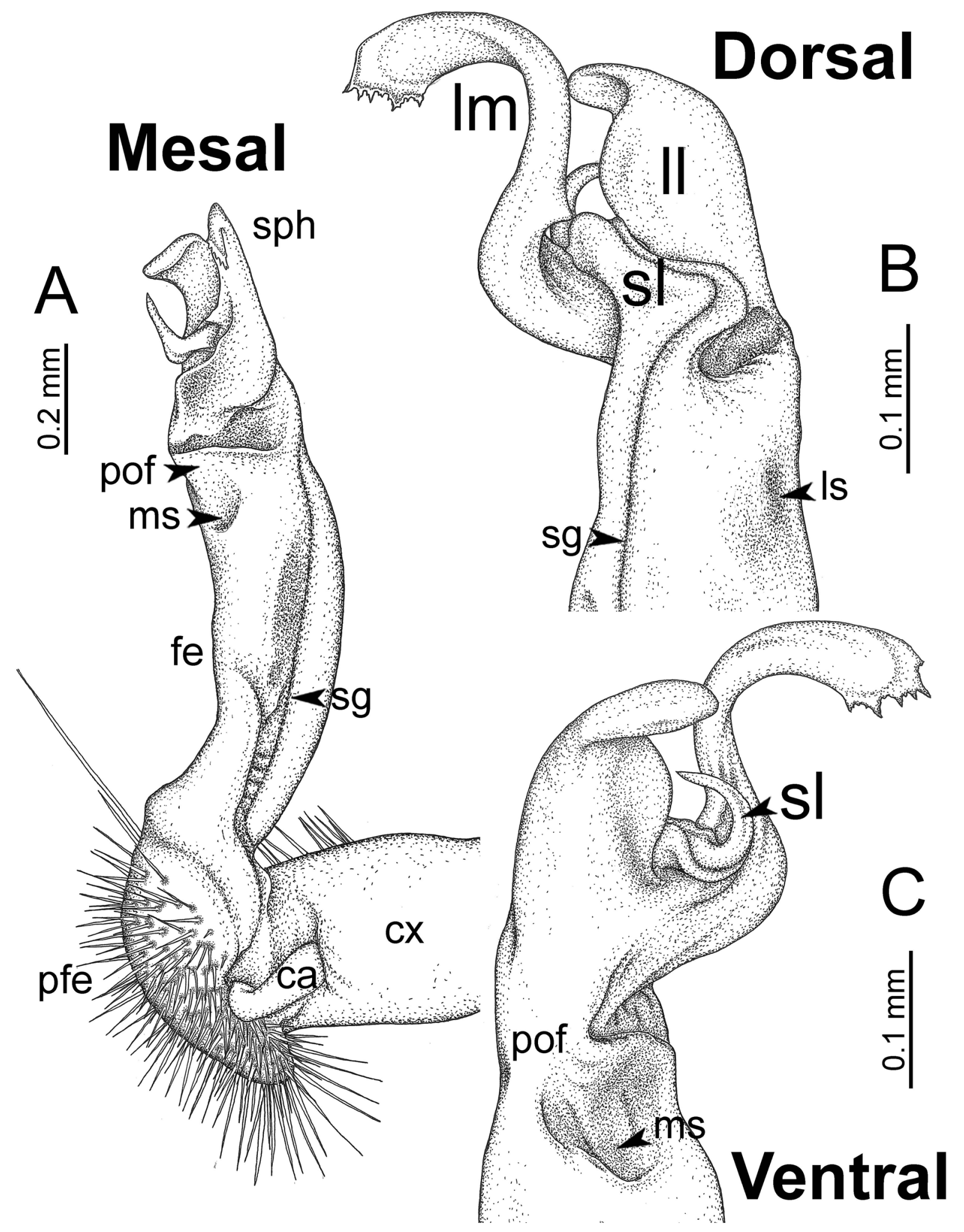

Fig. 4. Diagrammatic drawing of right gonopod of Nagaxytes Srisonchai, Enghoff \& Panha gen. nov. - N. gracilis Srisonchai, Enghoff \& Panha gen. et sp. nov., specimen from Wat Vimooddhi Wanaram, Thailand. A. Mesal view. B. Dorsal view. C. Ventral view. 


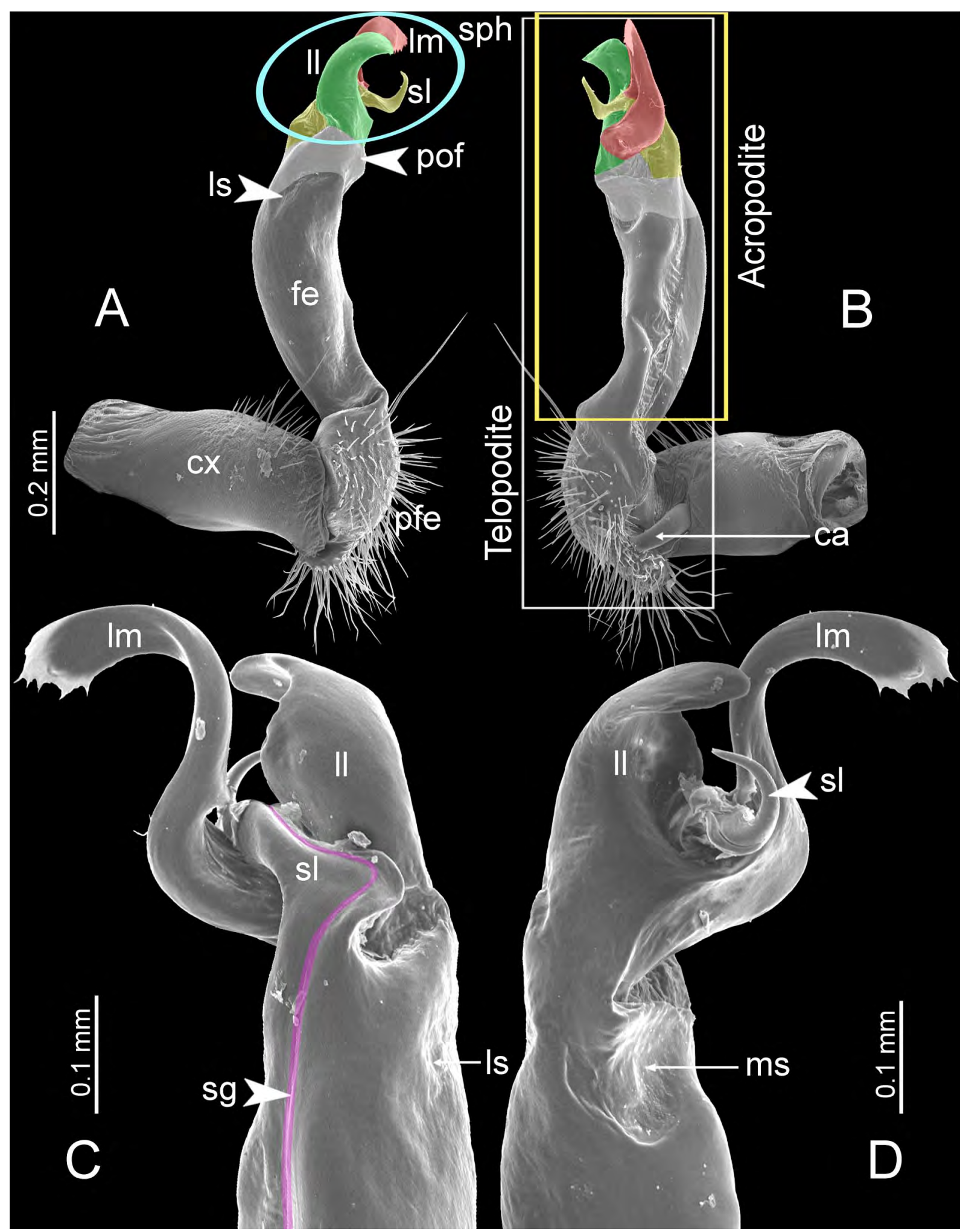

Fig. 5. SEM images of right gonopod of Nagaxytes Srisonchai, Enghoff \& Panha gen. nov. - N. gracilis Srisonchai, Enghoff \& Panha gen. et sp. nov., specimen from Wat Vimooddhi Wanaram, Thailand. A. Lateral view. B. Mesal view. C. Dorsal view. D. Ventral view. Colours: red = lamina medialis, green $=$ lamina lateralis, yellow $=$ solenomere, purple $=$ seminal groove . 


\section{Distribution and habitat}

This genus is known only from the western part of Thailand: Prachuap Khiri Khan Province (Hua Hin and Kui Buri Districts), Kanchanaburi Province (Sai Yok and Thong Pha Phum Districts) and Tak Province (Mae Sot and Umphang Districts) (Fig. 27). All four species seem to be local endemics, highly restricted to limestone habitats, and all have narrow distribution ranges. The specimens were usually found on humid rocks, rock walls, leaf litter or surface roots of trees. Some species can be found syntopically in the same habitat with other dragon millipede species.

\section{Key to species of Nagaxytes gen. nov. (based mainly on males)}

1. Gonopod with lamina lateralis long (e.g., Figs 15B, 16C, 20B, 21C), or with lobe (e.g., Figs 25B, 26C)

- Lamina lateralis short, swollen, stout, compact, without lobe (e.g., Figs 9B, 10C, F)

N. acantherpestes (Golovatch \& Enghoff, 1994) gen. et comb. nov.

2. Body length $22-26 \mathrm{~mm}$ in male, $24-28 \mathrm{~mm}$ in female. Lamina lateralis with a curved, long, spatulate lobe (Figs 25-26); solenomere terminating in two curved processes (Figs 25B, 26E)

N. spatula Srisonchai, Enghoff \& Panha gen. et sp. nov.

- Body length $30-36 \mathrm{~mm}$ in male, $35-38 \mathrm{~mm}$ in female. Lamina lateralis without spatulate lobe; solenomere terminating in one process (e.g., Figs 15D, 16D, 20D, 21D) 3

3. Metaterga 4-19 with conspicuous anterior row of tubercles/cones/spines (Fig. 13A-C). Sternal lobe between male coxae 4 subtrapeziform (Fig. 14J). Lamina lateralis erect, digitiform, thick, tip directed anteriad (Figs 15B-D, 16C, E-F)

N. erecta Srisonchai, Enghoff \& Panha gen. et sp. nov.

- Metaterga 4-19 without anterior row of tubercles/cones/spines (Fig. 18A-C). Sternal lobe between male coxae 4 not subtrapeziform, incompletely bilobed, tip deeply emarginate (Fig. 19J). Lamina lateralis lamella-like, curved, broad, thin, tip directed mesoventrad (Figs 20B-D, 21C-F)

N. gracilis Srisonchai, Enghoff \& Panha gen. et sp. nov.

\section{Species descriptions}

Nagaxytes acantherpestes (Golovatch \& Enghoff, 1994) gen. et comb. nov.

Figs 2, 6-10

Desmoxytes acantherpestes Golovatch \& Enghoff, 1994: 51-53, figs 21-28.

Desmoxytes acantherpestes - Enghoff 2005: 96. — Decker 2010: 28. — Nguyen \& Sierwald 2013: 1240.

\section{Diagnosis}

Metaterga 4-19 with one row of 2+2 posterior spines (anterior row absent). Similar in this respect to $N$. gracilis gen. et sp. nov. but differs from this species by having paraterga shorter; degree of elevation of paraterga lower; sternal lobe between male coxae 4 subtrapeziform; lamina lateralis swollen, stout, short.

\section{Material examined}

Holotype

THAILAND: $\widehat{\jmath}$, western coast of Siam Gulf (Gulf of Thailand), Hua Hin [Prachuap Khiri Khan Province, Hua Hin District], 8 Aug. 1979, B. Petersen leg. (ZMUC 000101457). 

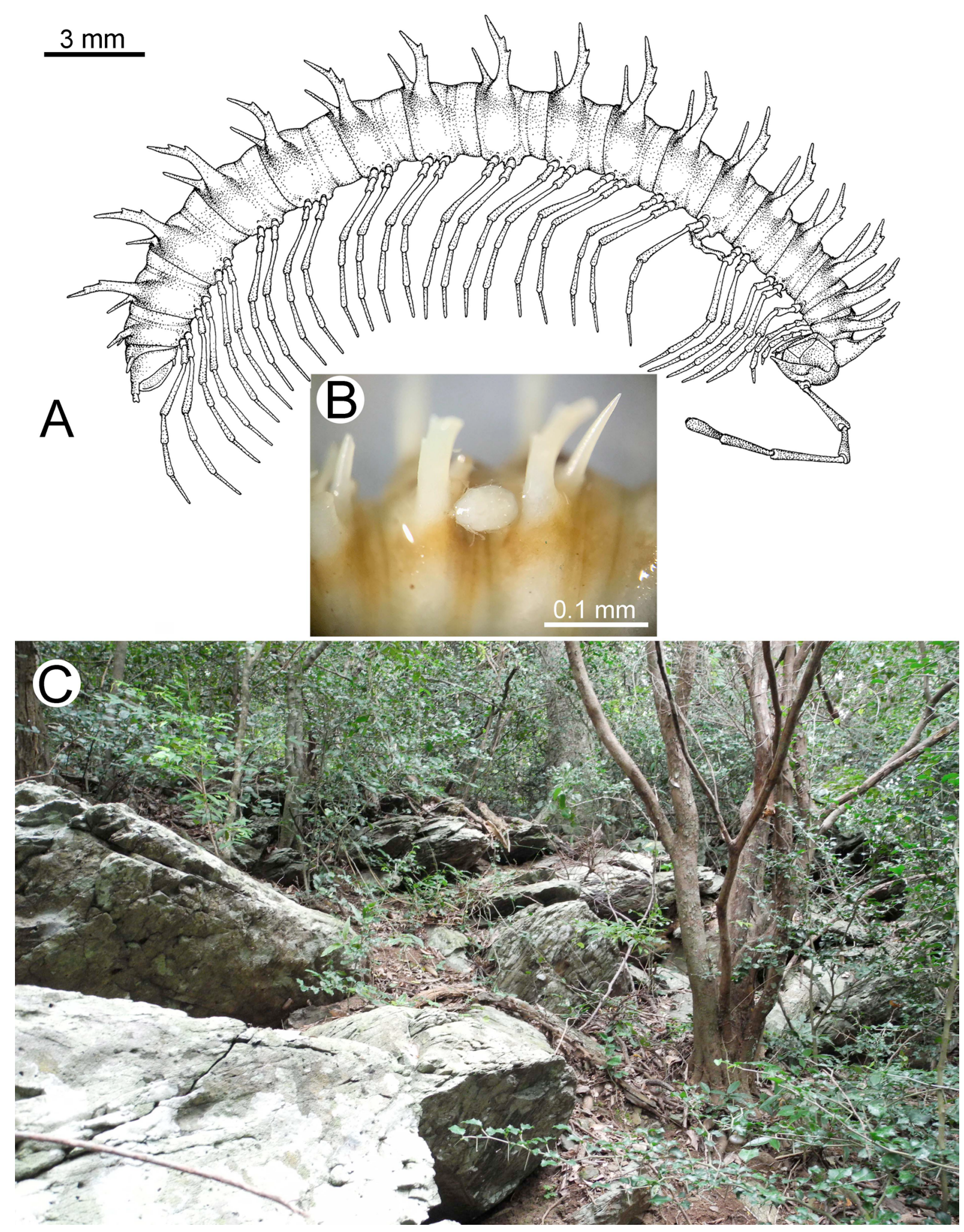

Fig. 6. Nagaxytes acantherpestes (Golovatch \& Enghoff, 1994) gen. et comb. nov. A. Drawing of $\widehat{\partial}$, holotype (ZMUC 000101457). B. Parasitic mite. C. Habitat. 


\section{Other material}

THAILAND: $2 \hat{\jmath} \widehat{\partial}, 1 \hat{\jmath}$ (gonopods lost), 1 을 Prachuap Khiri Khan Province, Kui Buri District, Hat

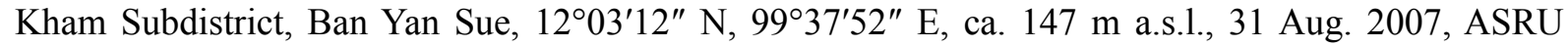
members leg. (CUMZ).

\section{Redescription}

SizE. Length 32-34 mm (male), $36 \mathrm{~mm}$ (female); width of midbody metazona ca. $2.2 \mathrm{~mm}$ (male), $3.0 \mathrm{~mm}$ (female). Width of head $<$ body ring $2=3<$ collum $<4<5-16$, thereafter body gradually tapering towards telson.

Colour. Specimens in life brown. Colour in alcohol: after 29 years changed to pale brown; head, antennae, collum, metaterga, surface below paraterga, sterna, epiproct pale brown; paraterga brownish white.

Collum (Fig. 7A). With setae in anterior row and intermediate row, spines in posterior row; paraterga of collum elevated at ca. $35-40^{\circ}$, directed caudolaterad, with two conspicuous notches at lateral margin.

Antennae (Fig. 7D). Moderately long and slender, reaching to body ring 5 or 6 (male) and 5 (female) when stretched dorsally.

Tegument. Quite dull. Stricture between prozona and metazona shallow, wide.

Metaterga (Fig. 7A-C). With one or two transverse rows of setae and spines; metatergum 2 with ?1+?1 anterior setae (inconspicuous) and 2+2 posterior spines; metaterga 3-19 with 2+2 posterior spines (lateral spines very long).

Pleurosternal carinae. On body ring 2 long, crest-like; on body ring 3 a small ridges; thereafter missing.

Paraterga (Figs 7F-G, 8B). Directed caudolaterad on body rings $2-18$, elevated at ca. $60^{\circ}$ (male) $50^{\circ}-$ $60^{\circ}$ (female), directed increasingly caudad on body ring 19 .

TELsON (Fig. 8C-G). Epiproct quite short; tip usually subtruncate (in some specimens slightly emarginate); lateral setiferous tubercles conspicuous, long, digitiform; apical tubercles conspicuous. Hypoproct subtriangular; caudal margin subtriangular, with inconspicuous setiferous tubercles.

Sterna (Fig. 8H-J). Cross-impressions quite deep. Sternal lobe between male coxae 4 swollen, subtrapeziform when seen in caudal view; base broad; tip slightly or deeply emarginate.

Gonopods (Figs 9, 10). Coxa subequal in length to femur. Cannula long and slender. Telopodite quite long and slender. Prefemoral part ca. $2 / 3$ as long as femur. Femur quite long and slender. Mesal sulcus conspicuous, deep, wide; lateral sulcus conspicuous, very deep. Postfemoral part conspicuous, quite short. Solenophore well-developed: lamina lateralis swollen, stout, short, compact: lamina medialis very long; with a swollen base, gradually becoming thinner towards tip; apically fringed with several small spines; tip directed mesoventrad. Solenomere quite long, curved, tip directed ventrad.

\section{Distribution and habitat}

This species is known from two locations (Hua Hin and Ban Yan Sue) in Prachuap Khirikhan Province. We believe that the holotype was probably collected from limestone habitats because the type locality (near Hua Hin) lies in a limestone area. Specimens collected by us were from limestone habitats. It has been found crawling on rocks or on leaf litter. 


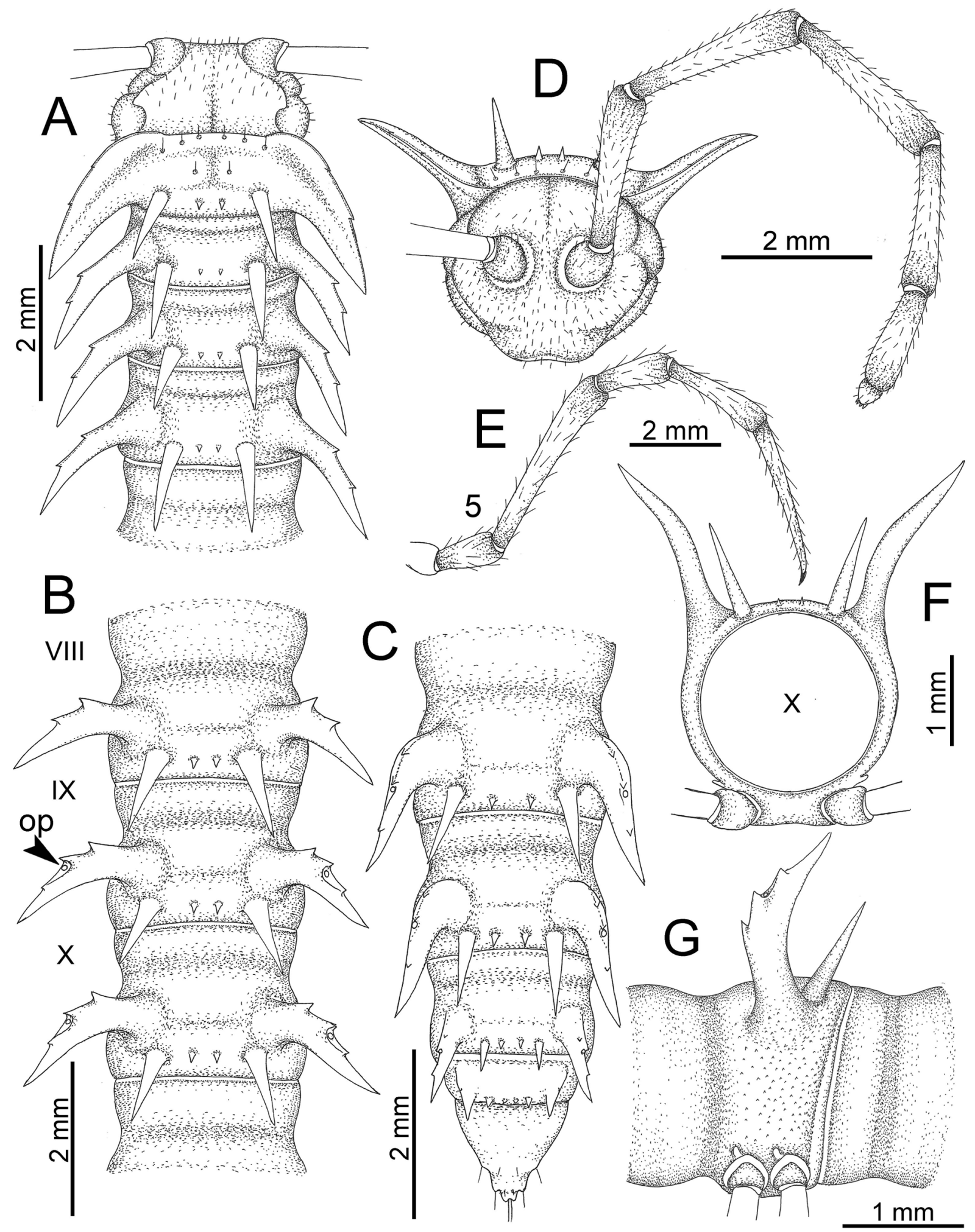

Fig. 7. Nagaxytes acantherpestes (Golovatch \& Enghoff, 1994) gen. et comb. nov., §, holotype (ZMUC 000101457). A. Anterior body part. B. Body rings 8-10. C. Posteriormost body rings and telson. D. Head and antenna. E. $\delta$ leg 5 (right). F-G. Midbody ring. 

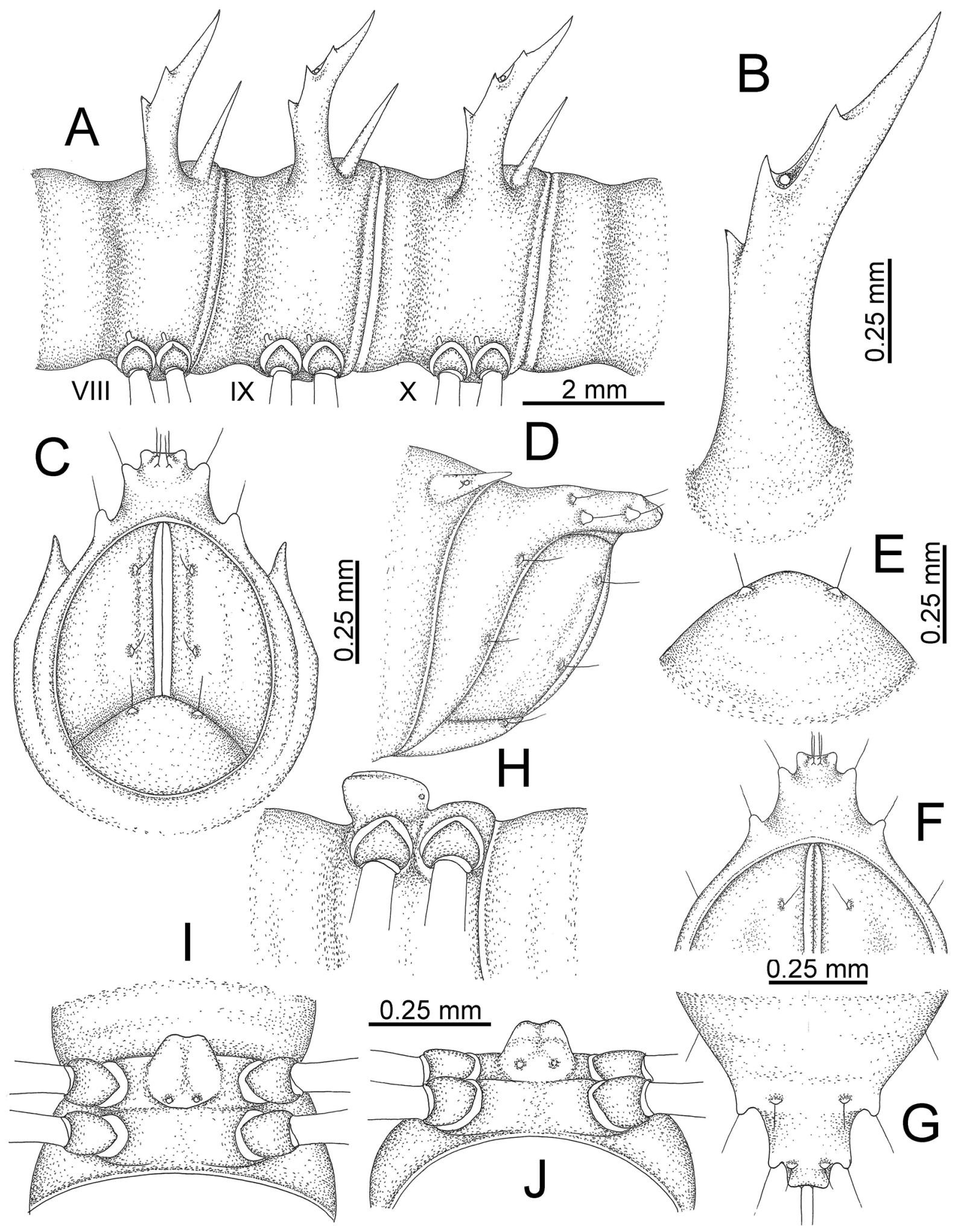

Fig. 8. Nagaxytes acantherpestes (Golovatch \& Enghoff, 1994) gen. et comb. nov., §, holotype (ZMUC 000101457). A. Body rings 8-10. B. Paraterga of ring 10. C-D. Last ring and telson. E. Hypoproct. F-G. Epiproct. H-J. Sternal lobe between coxae 4. 


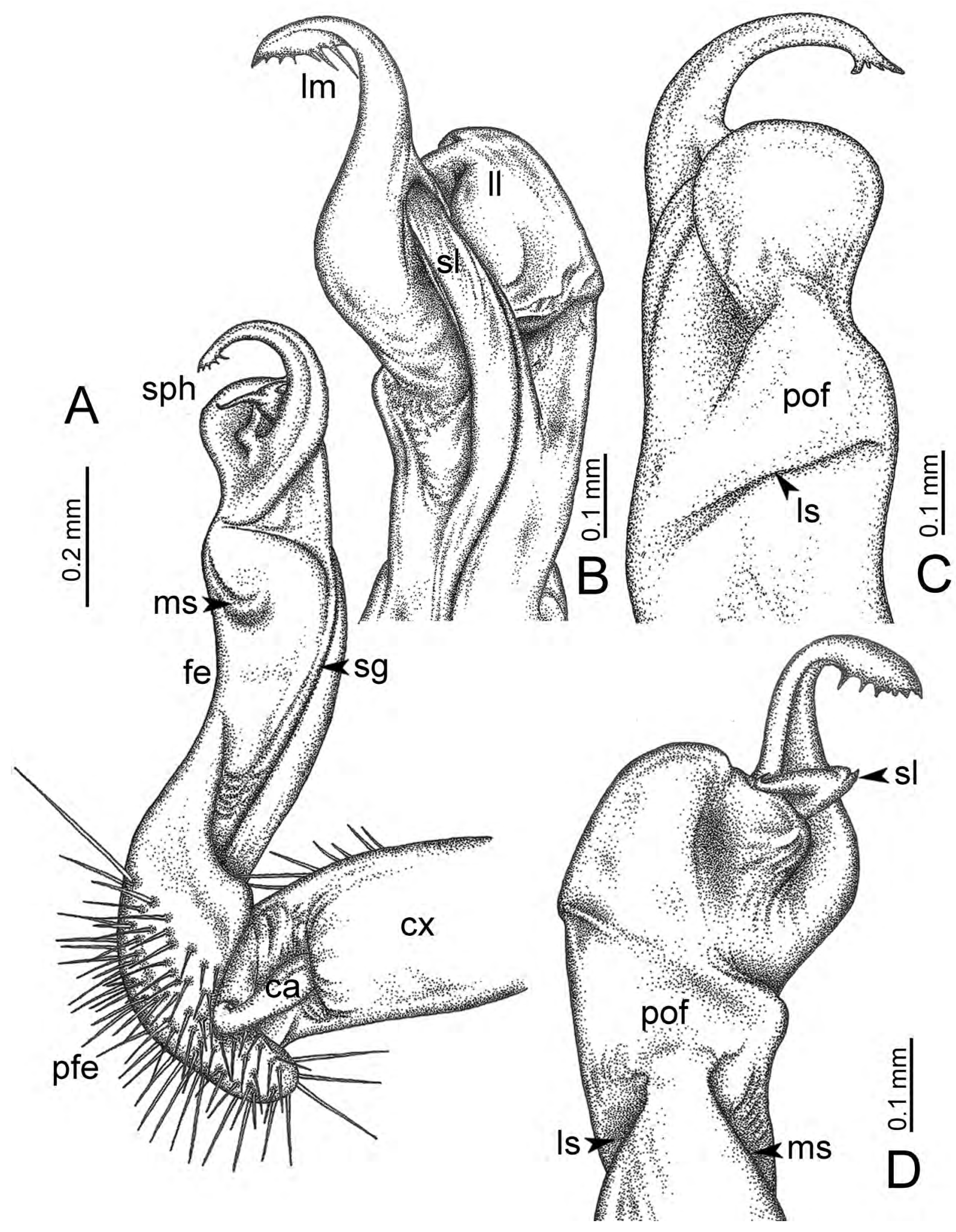

Fig. 9. Nagaxytes acantherpestes (Golovatch \& Enghoff, 1994) gen. et comb. nov., specimen from Ban Yan Sue (Thailand), right gonopod. A. Mesal view. B. Dorsal view. C. Lateral view. D. Ventral view. 


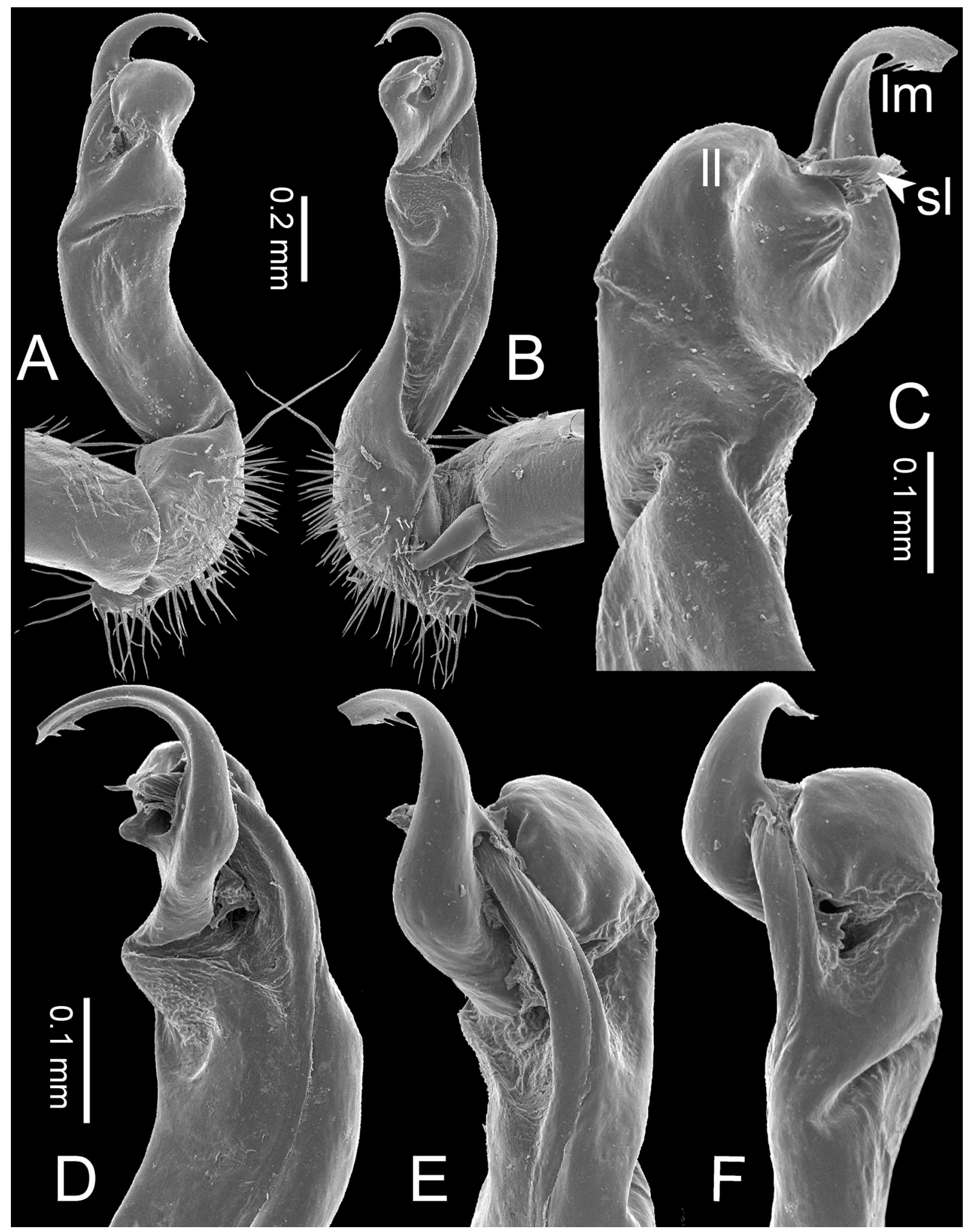

Fig. 10. Nagaxytes acantherpestes (Golovatch \& Enghoff, 1994) gen. et comb. nov., specimen from Ban Yan Sue (Thailand), right gonopod. A. Lateral view. B. Mesal view. C. Ventral view. D, F. Subdorsal view. E. Dorsal view. 
This species is likely to be syntopic with Desmoxytes planata (Pocock, 1895) at Ban Yan Sue; however, we noticed that the habitats of these two species are clearly different. Nagaxytes acantherpestes gen. et comb. nov. lives on the ground or on limestone rocks while D. planata was found on tree trunks near garbage.

Decker (2010) identified one male in NHMG, collected from Thanboke Khorani National Park, Krabi Province ( $\left.8^{\circ} 23^{\prime} 12^{\prime \prime} \mathrm{N}, 98^{\circ} 44^{\prime} 16^{\prime \prime} \mathrm{E}\right)$ as $D$. acantherpestes. This specimen might perhaps be 'D. ' gigas Golovatch \& Enghoff, 1994 (in the 'gigas' group) because the location falls in the distribution range for this group in South Thailand whereas Nagaxytes gen. nov. (the 'acantherpestes' group) is limited to western Thailand. Moreover, Thanboke Khorani National Park and Hua Hin are far apart, about 500 km.

This species is distributed in a narrow area; we regard $N$. acantherpestes gen. et comb. nov. as endemic to Prachuap Khiri Khan Province, Thailand.

\section{Remarks}

In the original description, Golovatch \& Enghoff (1994) did not comment on the live colouration of this species. We did not photograph living specimens, but our collector noticed a brown colouration. Golovatch \& Enghoff (1994) also described D. acantherpestes as lacking pleurosternal carinae, but after we re-examined the holotype and examined all newly collected specimens, we found the pleurosternal carinae as crest-like on ring 2 , as small ridges on ring 3 , thereafter absent. There is a variation in the tip of the epiproct which in some specimens is subtruncate, in others slightly emarginate.

On some specimens we found parasitic mites, probably of the genus Leptus Latreille, 1795 (Fig. 6B). The mites infested the millipede on the metaterga. This association reminds us of what Srisonchai et al. (2018) found in Desmoxytes cervina (Pocock, 1895): several engorged Leptus mites attached to the millipede body.

Nagaxytes erecta Srisonchai, Enghoff \& Panha gen. et sp. nov. urn:1sid:zoobank.org:act:914BBC06-157C-419B-8B66-EBD18475B5BC

Figs 3, 11-16

\section{Diagnosis}

Metaterga 2-8 with two rows of spines $(1+1$ or $2+2$ spines in anterior row, $2+2$ spines in posterior row). Similar in this respect to $N$. spatula gen. et sp. nov. but differs by having: degree of elevation of paraterga lower; apical tubercles of epiproct conspicuous; surface near lateral sulcus without ridge (not swollen); lamina lateralis erect, long, thick, digitiform, tip round and directed anteriad; lamina medialis very long, apically fringed.

\section{Etymology}

The name is a Latin adjective and refers to the erect lamina lateralis of the gonopod telopodite.

\section{Material examined}

\section{Holotype}

THAILAND: $\sigma^{\wedge}$, Kanchanaburi Province, Thong Pha Phum District, Phuphrai Thannam Resort, 14²4'0.6" N, 98 38'36" E, ca. 112 m a.s.1., 17 Aug. 2016, ASRU members leg. (CUMZ-pxDGT00001).

\section{Paratypes}

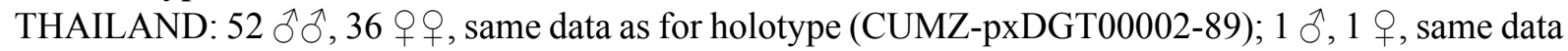
as for holotype (ZMUC 00040244); 1 ठ, 1 q, same data as for holotype (ZMUM); 1 ○, 1 q, same data as for holotype (NHMW); $1 \AA, 1$, same data as for holotype (NHMUK). 


\section{Further specimens, not paratypes}

THAILAND - Kanchanaburi Province: Thong Pha Phum District: $1 \delta^{\lambda}$ (gonopods lost), 4 우,

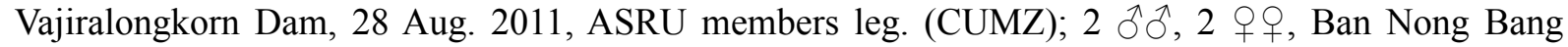

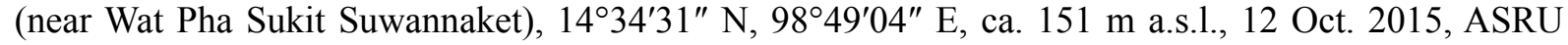

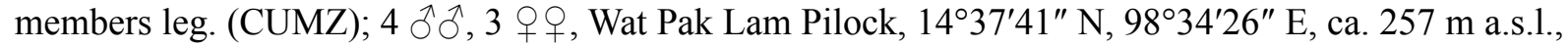

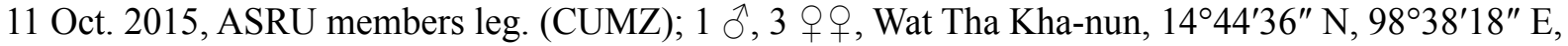
ca. 114 m a.s.l., 24 Jul. 2016, P. Pimvichai, P. Prasankok and N. Nantarat leg. (CUMZ); 12 §

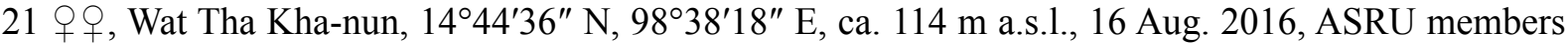

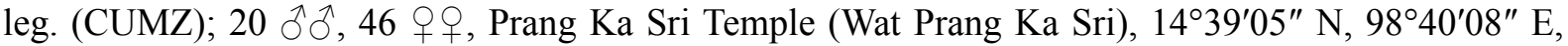
ca. 106 m a.s.1., 15 Aug. 2016, leg. ASRU members (CUMZ). - Sai Yok District: 1 broken $\widehat{\overbrace{}}$ (gonopods lost), Daowadueng Cave, $14^{\circ} 28^{\prime 2} 3^{\prime \prime}$ N, 98 $50^{\circ} 04^{\prime \prime}$ E, ca. 133 m a.s.1., 8 Sep. 2008, ASRU members

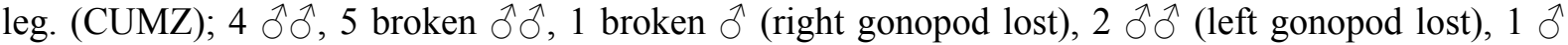
(remaining rings 1-8), 10 우, 1 juvenile, Daowadueng Cave, 14²8 $23^{\prime \prime} \mathrm{N}, 98^{\circ} 50^{\prime} 04^{\prime \prime} \mathrm{E}$, ca. $133 \mathrm{~m}$

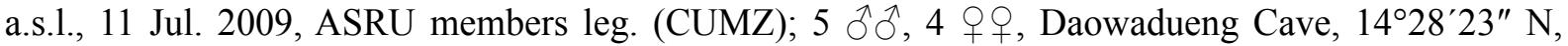

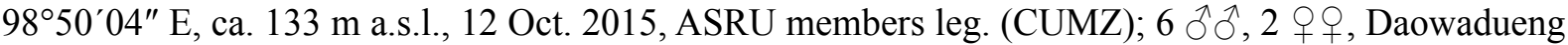

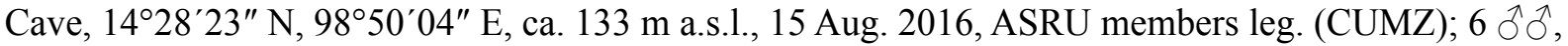

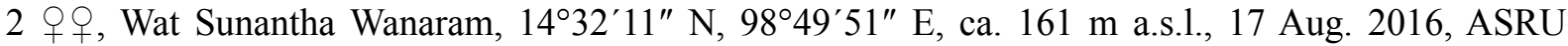
members leg. (CUMZ).

\section{Description}

SizE. Length $32-36 \mathrm{~mm}$ (male), 36-38 mm (female); width of midbody metazona ca. $2.4 \mathrm{~mm}$ (male), $3.4 \mathrm{~mm}$ (female). Width of head $<$ collum $<$ body ring $2=3<4<5-17$, thereafter body gradually tapering towards telson.

Colour (Figs 11, 12A-C). Specimens in life falling into two colour morphs: Reddish brown morph - body reddish brown; paraterga pinkish red; collum, metaterga and epiproct reddish brown; head, antennae (except whitish distal part of antennomere 7 and antennomere 8), prozona, surface below paraterga, sterna and legs brown; a few basal podomeres whitish brown. Brown morph - body brown; paraterga pinkish red; head, antennae (except whitish distal part of antennomere 7 and antennomere 8), collum, prozona, metaterga, epiproct and legs brown; paraterga and sterna pale brown; surface below paraterga brown or dark brown; a few basal podomeres whitish brown. Colour in alcohol: after 3-10 years changed to pale brown; head, antennae, collum, metaterga, surface below paraterga, sterna, epiproct, legs pale brown or whitish brown; paraterga brownish white.

Collum (Fig. 13A). With three transverse rows of setiferous tubercles and spines, $3+3$ tubercles in anterior row, $1+1$ tubercles in intermediate row and $2+2$ spines in posterior row; paraterga of collum long and broad, elevated at ca. $40^{\circ}-45^{\circ}$ (male) $35^{\circ}-40^{\circ}$ (female), directed caudolaterad, with two conspicuous notches at lateral margin.

Antennae (Fig. 13D). Moderately long and slender, reaching to body ring 5 or 6 (male) and 4 or 5 (female) when stretched dorsally.

Tegument. Quite dull. Stricture between prozona and metazona shallow, wide.

Metaterga (Fig. 13A-C). With two transverse rows of cones and spines; metaterga 2-15 with 2+2 anterior spines and $2+2$ posterior spines (posterior spines longer and thicker than anterior ones; lateral spines of posterior row very long); metaterga 16-18 with $2+2$ anterior cones/spines and $2+2$ posterior cones/spines (brown morph - anterior cones/spines inconspicuous; lateral spines of posterior row very long); metatergum 19 with $1+1$ anterior small tubercles/cones and $2+2$ posterior spines (brown morph anterior tubercles/cones poorly developed). 

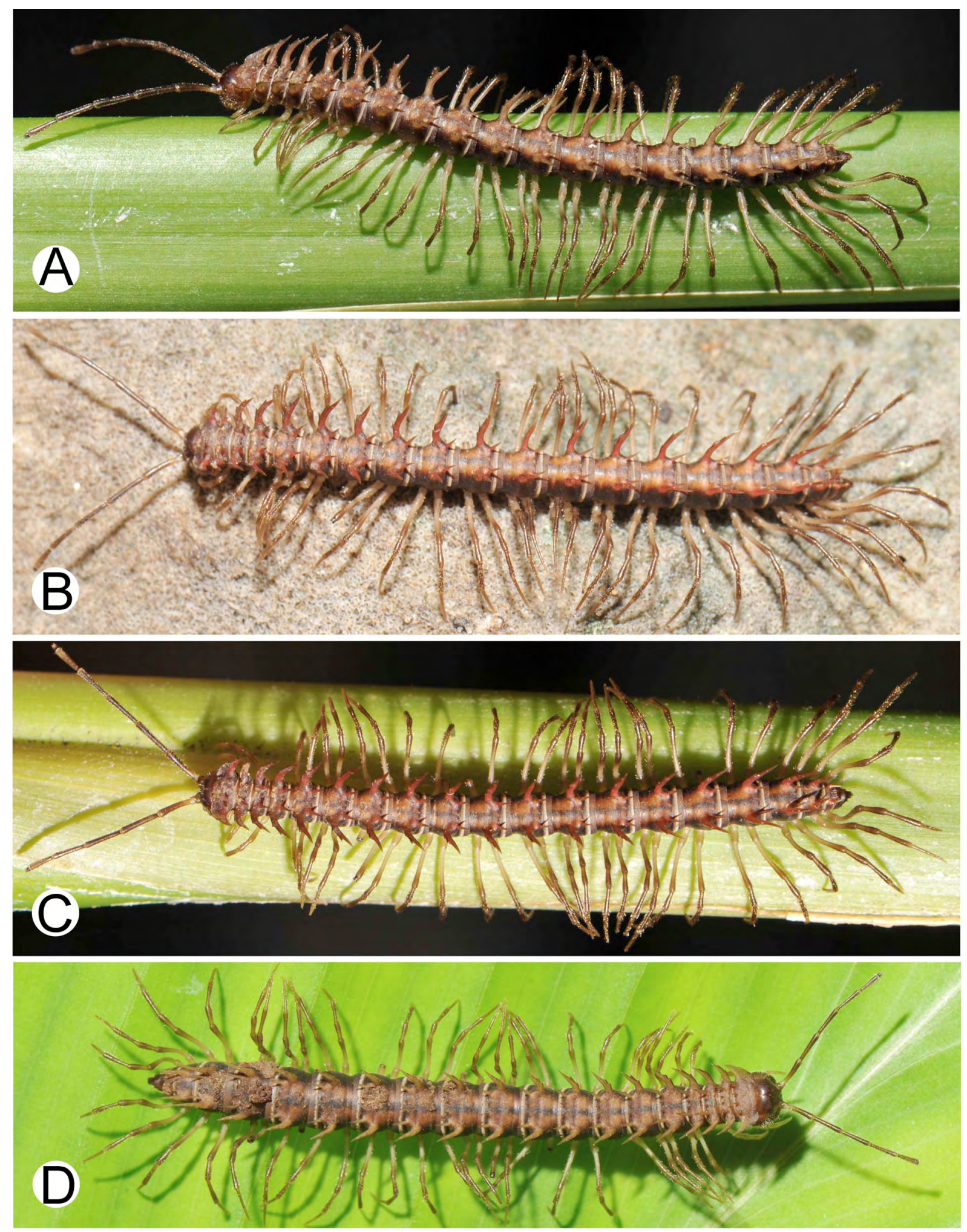

Fig. 11. Live photographs of Nagaxytes erecta Srisonchai, Enghoff \& Panha gen. et sp. nov. A-B. Specimens from Phuphrai Thannam Resort, Thailand ( ${ }^{\lambda} \delta$, CUMZ-pxDGT00002-3). C. Specimen from Ban Nong Bang, Thailand $\left({ }^{\Uparrow}\right)$. D. Specimen from Phuphrai Thannam Resort, Thailand (, , CUMZpxDGT00054). 

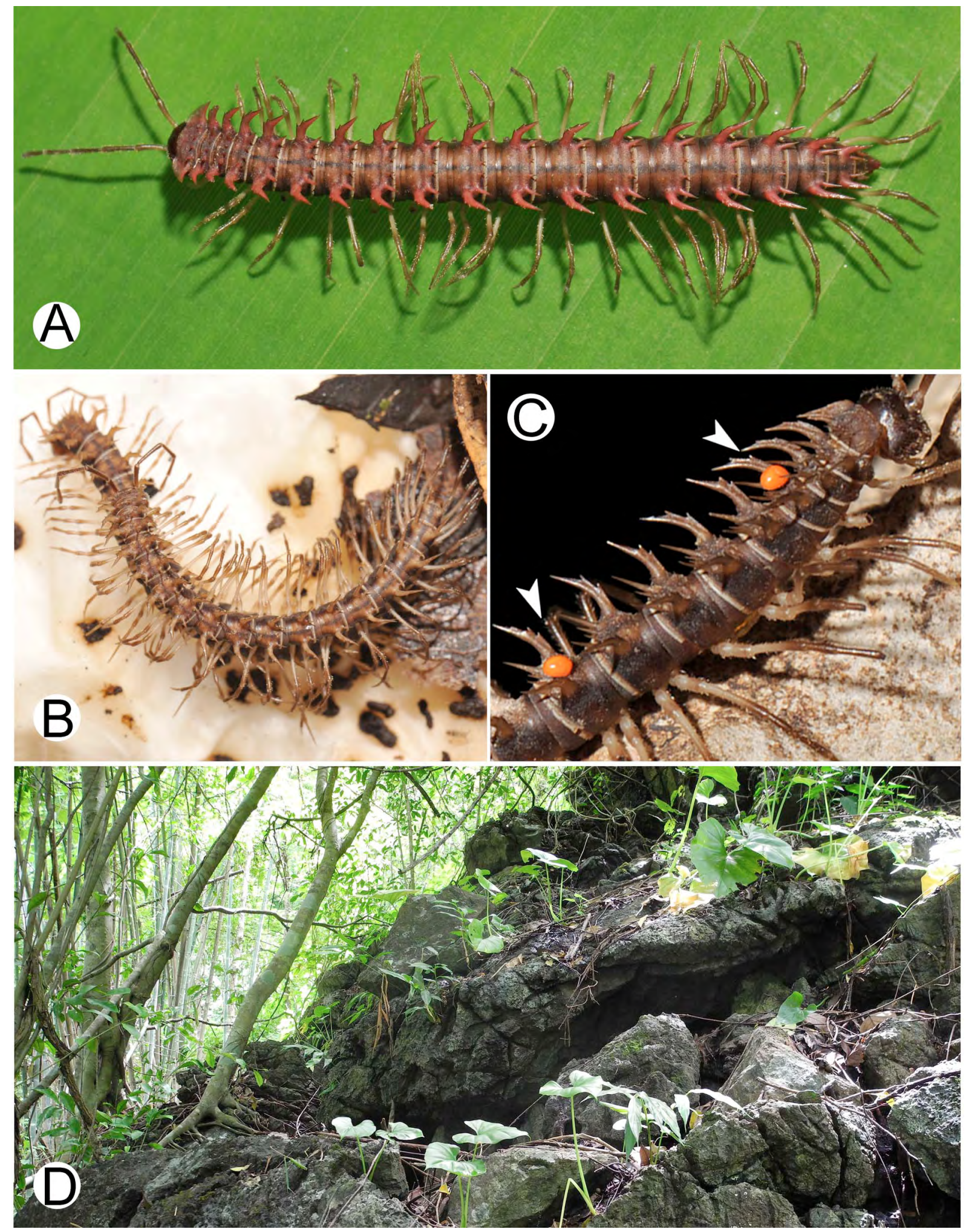

Fig. 12. Live photographs and habitat of Nagaxytes erecta Srisonchai, Enghoff \& Panha gen. et sp. nov. A. Specimen from Ban Nong Bang, Thailand (q). B. Mating couple. C. $\widehat{\partial}$ with parasitic mites. D. Habitat. 


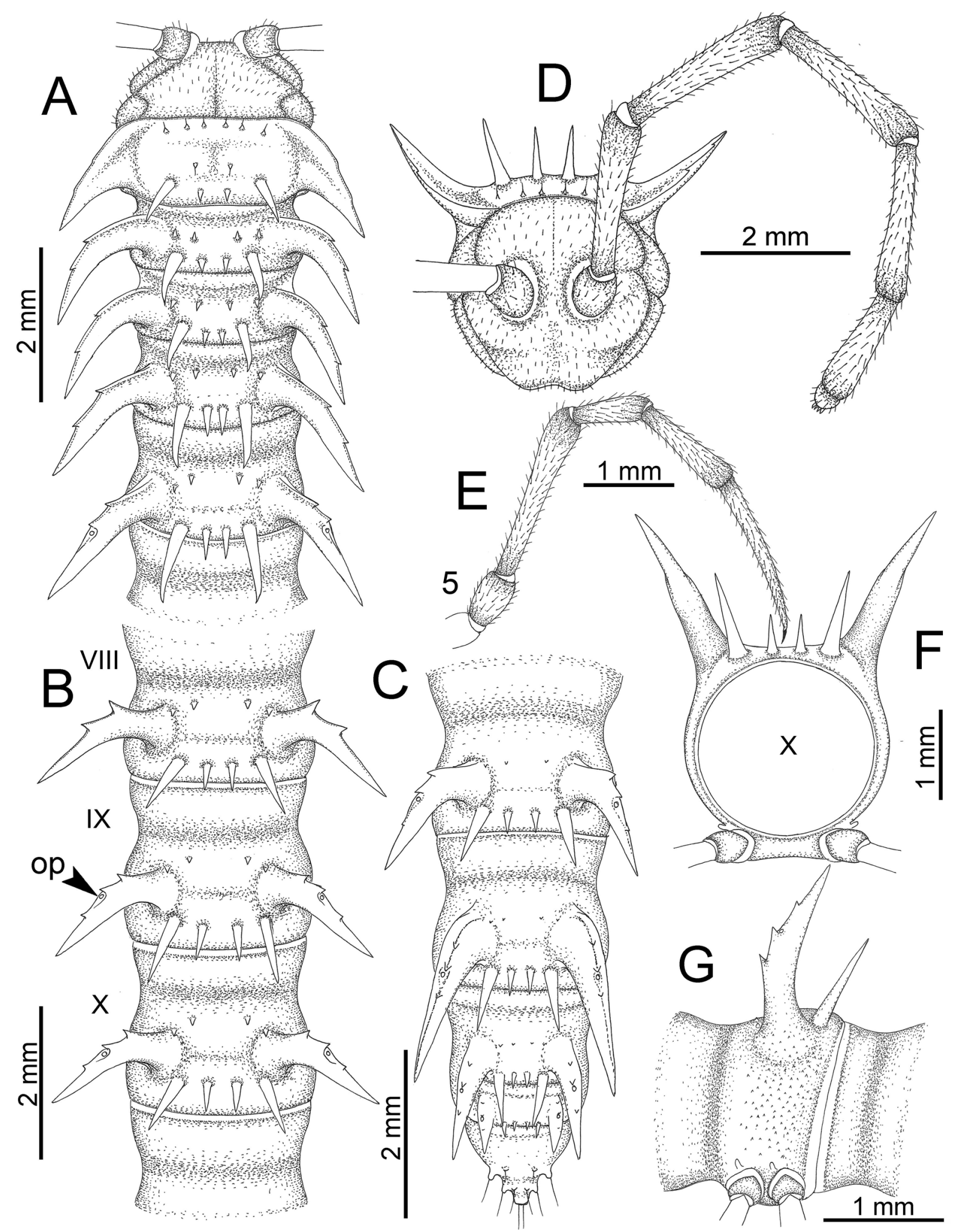

Fig. 13. Nagaxytes erecta Srisonchai, Enghoff \& Panha gen. et sp. nov., $\widehat{O}$, paratype (CUMZpxDGT00002). A. Anterior body part. B. Body rings 8-10. C. Posteriormost body rings and telson. D. Head and antenna. E. $\overbrace{}^{\Uparrow}$ leg 5 (right). F-G. Midbody ring. 


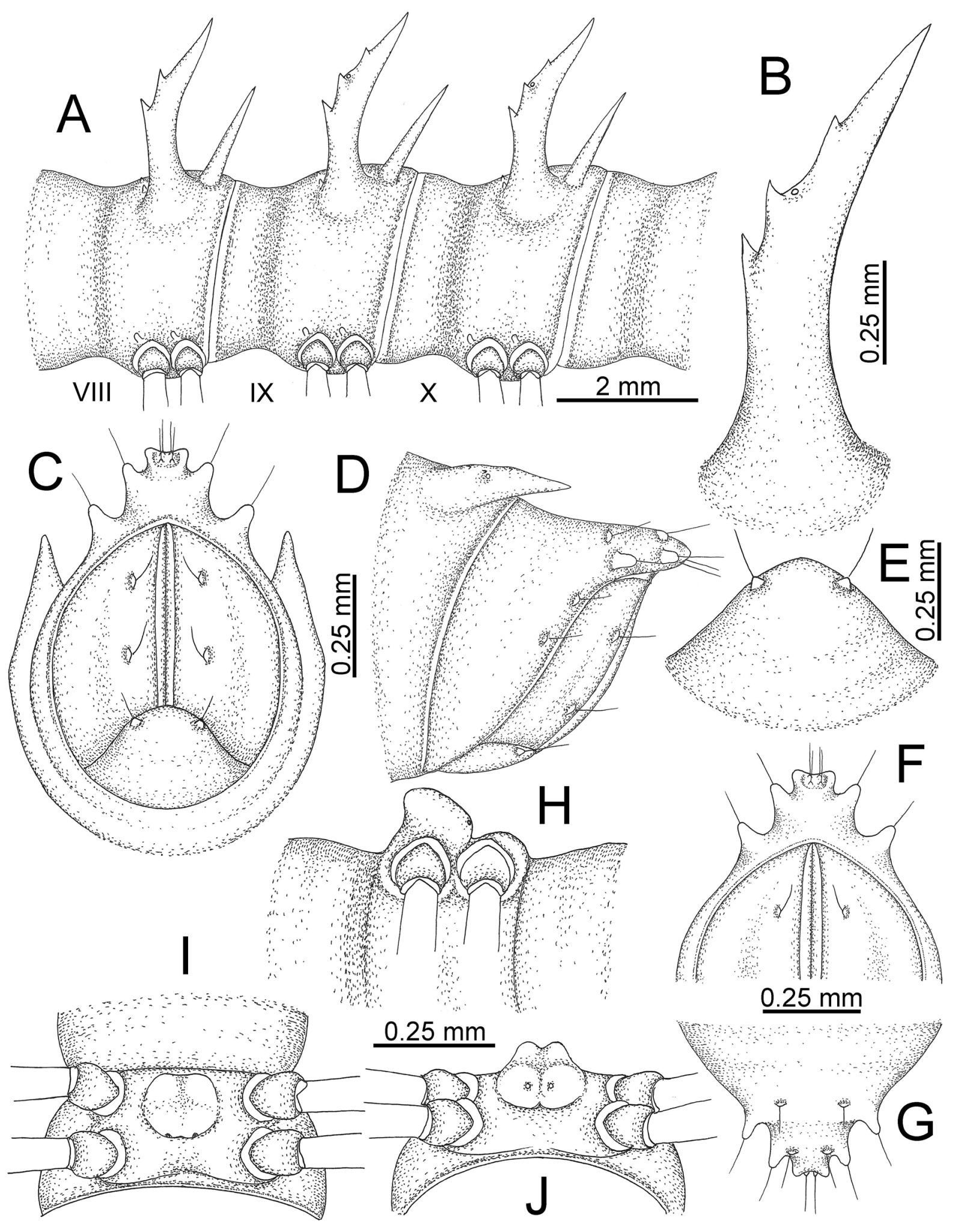

Fig. 14. Nagaxytes erecta Srisonchai, Enghoff \& Panha gen. et sp. nov., $\partial^{\lambda}$, paratype (CUMZpxDGT00002). A. Body rings 8-10. B. Paraterga of ring 10. C-D. Last ring and telson. E. Hypoproct. F-G. Epiproct. H-J. Sternal lobe between coxae 4. 
Pleurosternal carinae. On body ring 2 long, crest-like; on ring 3 long ridges; on ring 4 small ridges; thereafter missing.

Paraterga (Figs 13F-G, 14B). Directed caudolaterad on body rings $2-17$, elevated at ca. $60^{\circ}-70^{\circ}$ (male) $50^{\circ}-60^{\circ}$ (female), directed increasingly caudad on body rings $18-19$.

TELsON (Fig. 14C-G). Epiproct quite short; tip usually subtruncate (in some specimens slightly emarginate); lateral setiferous tubercles conspicuous, long, digitiform; apical tubercles conspicuous. Hypoproct usually subtriangular (in some specimens subtrapeziform); caudal margin subtriangular or round, with conspicuous setiferous tubercles.

STERNA (Fig. 14H-J). Cross-impressions quite deep. Sternal lobe between male coxae 4 subtrapeziform, stout; base broad; tip emarginate.

Gonopods (Figs 15, 16). Coxa subequal in length to femur. Cannula long and slender. Telopodite quite long and slender. Prefemoral part ca. half as long as femur. Femur quite long and slender, slightly enlarged distad. Mesal sulcus conspicuous, deep, wide; lateral sulcus quite deep and wide. Postfemoral part conspicuous, short. Solenophore well-developed: lamina lateralis erect, long, thick, digitiform; tip round, directed anteriad: lamina medialis very long; apically fringed with several small spines; tip directed mesad. Solenomere long and slender, tip directed anterolateriad.

\section{Distribution and habitat}

Nagaxytes erecta gen. et sp. nov. is known only from Kanchanaburi Province, Thailand. All specimens were collected from limestone habitats during the rainy season (July-October). Lots of specimens were usually found near human areas, where some habitats were being destroyed for construction of a temple or bureau of monks.

At Daowadueng Cave, the new species lives syntopically with $N$. gracilis gen. et sp. nov. and Desmoxytes purpurosea Enghoff, Sutcharit \& Panha, 2007, in the same habitat. Desmoxytes planata was also found near the habitat of the new species at Phuphrai Thannam Resort and Wat Tha Kha-nun. We assume that D. planata occurs in a different microhabitat because the areas where we collected it are very strongly influenced by humans, and all specimens were seen crawling on statues and concrete.

We have only found $N$. erecta gen. et sp. nov. in a narrow area $\left(100 \mathrm{~km}^{2}\right)$ along the huge limestone mountain range in Sai Yok and Thong Pha Phum Districts. Therefore, we regard this species as endemic for the Thai fauna.

\section{Remarks}

There is a considerable variation in the live colouration; two colour morphs can be distinguished brownish red and brown. All specimens from Ban Nong Bang (near Wat Pha Sukit Suwannaket) show a brownish red colour whereas specimens from the remaining localities exhibit a brown colour (except at Daowadueng Cave: both reddish brown and brown colour morphs occur in the same place, even the same habitat). A further morphological difference between these two colour morphs concerns the size of cones/spines (anterior row) on metaterga 16-19: conspicuous in the reddish brown colour morph, inconspicuous in the brown morph. However, the gonopod characters are virtually identical. A similar phenomenon is also found in Desmoxytes cervina in which two colour morphs share identical gonopod characters (Srisonchai et al. 2018). Therefore, we regard the differences in colour as interpopulational variation. An intrapopulational variation was also found in the:

- tip of epiproct: in some specimens subtruncate, in others slightly emarginate.

- shape of hypoproct: in some individuals subtriangular, in others subtrapeziform. 


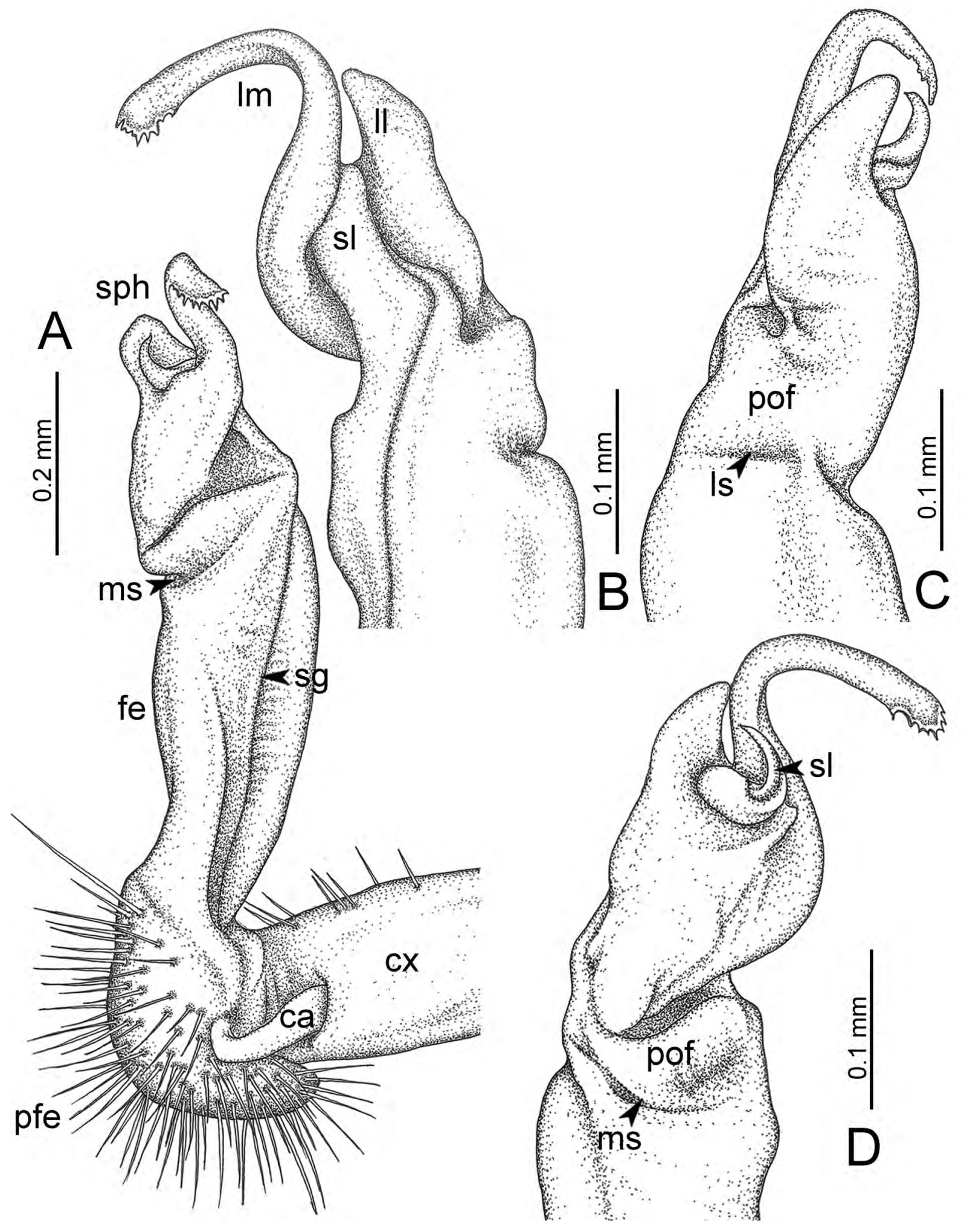

Fig. 15. Nagaxytes erecta Srisonchai, Enghoff \& Panha gen. et sp. nov. (paratype, CUMZ-pxDGT00002), right gonopod. A. Mesal view. B. Dorsal view. C. Lateral view. D. Ventral view. 


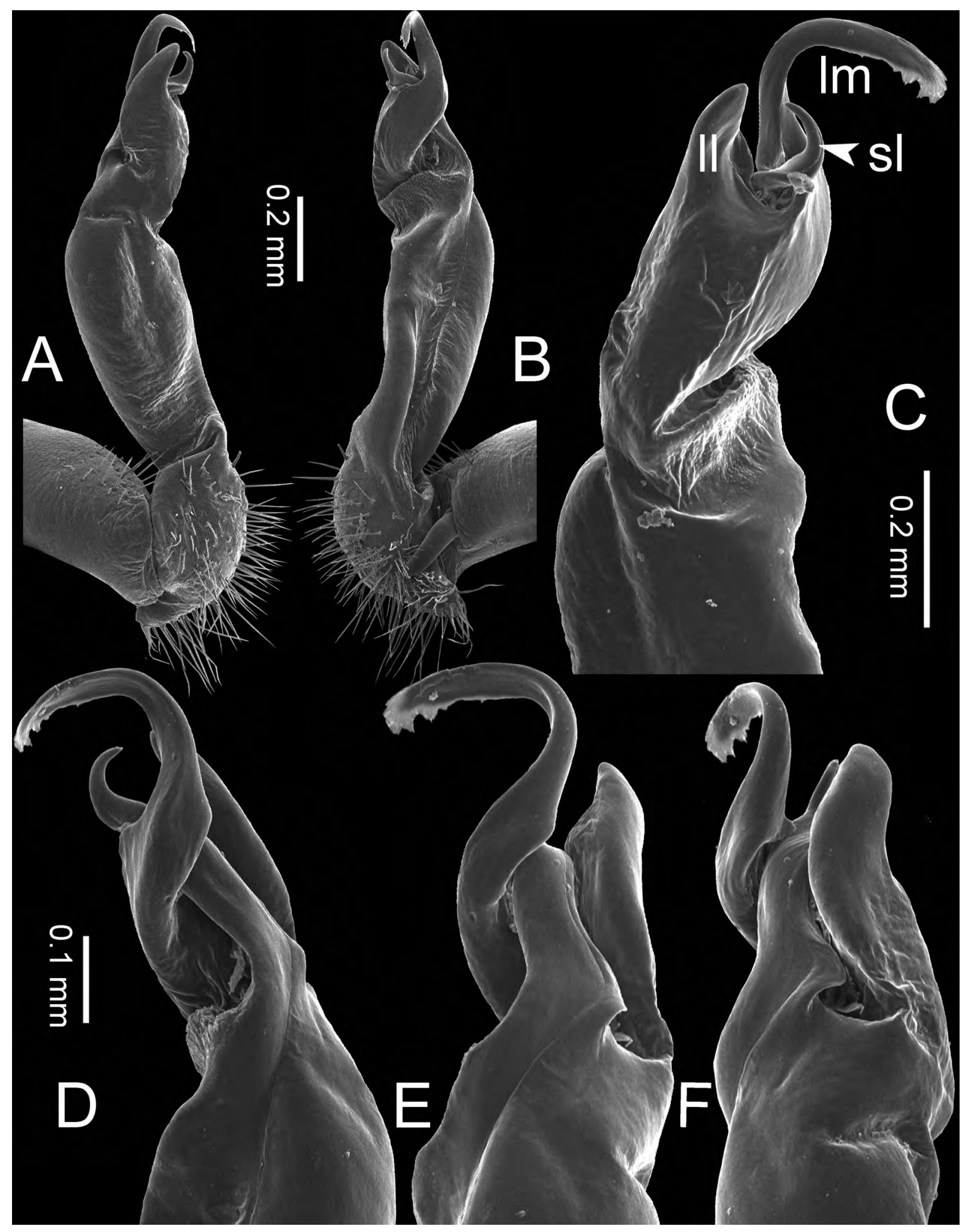

Fig. 16. Nagaxytes erecta Srisonchai, Enghoff \& Panha gen. et sp. nov. (paratype, CUMZpxDGT00002), right gonopod. A. Lateral view. B. Mesal view. C. Ventral view. D, F. Subdorsal view. E. Dorsal view. 
Some specimens of this species are infested by engorged mites (possibly of the genus Leptus) (Fig. 12C), as also found on D. cervina by Srisonchai et al. (2018) and N. acantherpestes gen. et comb. nov. as mentioned above.

Nagaxytes gracilis Srisonchai, Enghoff \& Panha gen. et sp. nov. urn:1sid:zoobank.org:act:A6CF5E48-B6AF-4FBD-A02D-D07E4DCDD605

Figs 1, 4, 5, 17-21

\section{Diagnosis}

Metaterga 4-19 with one row of $2+2$ posterior spines (anterior row absent). Similar in this respect to $N$. acantherpestes gen. et comb. nov., but differs from this species by having paraterga longer; degree of elevation of paraterga higher; sternal lobe between male coxae 4 incompletely bilobed; lamina lateralis long, lamella-like, thin, slender, tip round and directed ventrad.

\section{Etymology}

The name is a Latin adjective, referring to the slender lamina lateralis of the gonopod telopodite.

\section{Material examined}

\section{Holotype}

THAILAND: ${ }^{\wedge}$, Kanchanaburi Province, Sai Yok District, Daowadueng Cave, $14^{\circ} 28^{\prime 2} 23^{\prime \prime}$ N, $98^{\circ} 50^{\prime} 04^{\prime \prime}$ E, ca. 133 m a.s.1., 15 Aug. 2016, ASRU members leg. (CUMZ-pxDGT00090).

\section{Paratypes}

THAILAND: $7 \hat{\jmath} \widehat{\partial}, 21$ $q$ q , same data as for holotype (CUMZ-pxDGT00091-118); $1 \hat{\partial}, 1$, , same data as for holotype (ZMUC 00040245).

\section{Further specimens, not paratypes}

THAILAND - Kanchanaburi Province, Sai Yok District: $1 \hat{\partial}, 1$ broken $\widehat{\partial}, 1$ broken $\widehat{\partial}$ (right gonopod

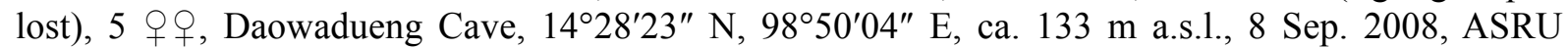

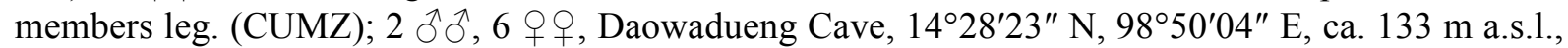

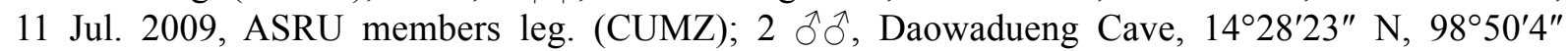
E, ca. $133 \mathrm{~m}$ a.s.1., 12 Oct. 2015, ASRU members leg. (CUMZ); 8 $\hat{\jmath}, 21$ 웅, 1 broken $\hat{\partial}, 1 \hat{\jmath}$ (right gonopod lost), $1 \delta^{\Uparrow}$ fragment (gonopods lost), Wat Tham Phrom Lok Khao Yai, $14^{\circ} 12^{\prime} 15^{\prime \prime} \mathrm{N}$, 99 07'57" E, ca. 122 m a.s.1., 9 Jul. 2009, ASRU members leg. (CUMZ); 1 ${ }^{\wedge}$, Wat Tham Phrom Lok Khao Yai, $14^{\circ} 12^{\prime} 15^{\prime \prime} \mathrm{N}, 9^{\circ} 07^{\prime} 57^{\prime \prime}$ E, ca. $122 \mathrm{~m}$ a.s.1., 15 Aug. 2016, ASRU members leg. (CUMZ); $1 \mathrm{O}^{\top}, \mathrm{Kra}$ Sae Cave, $14^{\circ} 06^{\prime} 05^{\prime \prime} \mathrm{N}, 9^{\circ} 10^{\prime} 09^{\prime \prime}$ E, ca. $79 \mathrm{~m}$ a.s.1., 10 Dec. 2006, ASRU members leg.

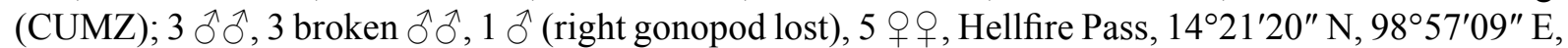

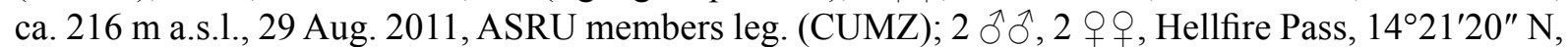
$98^{\circ} 57^{\prime} 09^{\prime \prime}$ E, ca. 216 m a.s.l., Aug. 2014, ASRU members leg. (CUMZ); 1 ㅅ, 1 ㅇ, Ban Thung Kang

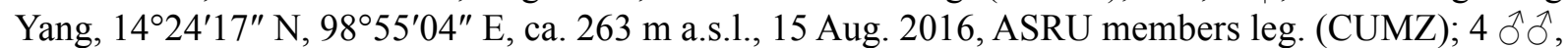

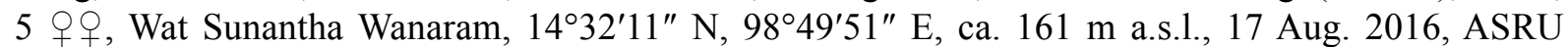
members leg. (CUMZ); 7 § $\delta^{2}, 6$ 우, Wat Phuttha Vimooddhi Wanaram (Wat Tham Phu Mood), $14^{\circ} 18^{\prime} 07^{\prime \prime} \mathrm{N}, 9^{\circ} 59^{\prime} 27^{\prime \prime}$ E, ca. 213 m a.s.1., 17 Aug. 2016, ASRU members leg. (CUMZ).

\section{Description}

Size. Length 30-33 mm (male), 35-38 mm (female); width of midbody metazona ca. $2.2 \mathrm{~mm}$ (male), $3.1 \mathrm{~mm}$ (female). Width of head $<$ collum $<$ body ring $2=3=4<5-17$, thereafter body gradually tapering towards telson. 
Colour (Fig. 17A-B). Specimens in life with body pinkish brown; paraterga vivid pink or reddish pink; collum, prozona, metaterga, surface below paraterga pinkish brown; head, antennae (except whitish distal part of antennomere 7 and antennomere 8) sterna and legs brown; a few basal podomeres whitish brown; epiproct pink. Colour in alcohol: after 3-9 years changed to pale brown; head, collum, metaterga, surface below paraterga, sterna, epiproct pale brown or whitish brown; paraterga brownish white.

Collum (Fig. 18A). With three transverse rows of setae/tubercles and spines, $3+3$ setae/tubercles in anterior row, $1+1$ setae/tubercles in intermediate row (tubercles small) and $2+2$ spines in posterior row; paraterga of collum long and broad, elevated at ca. $40^{\circ}-45^{\circ}$ (male) $35^{\circ}-40^{\circ}$ (female), directed caudolaterad, with 2 conspicuous notches at lateral margin.

Antennae (Fig. 18D). Moderately long and slender, reaching to body ring 5 or 6 (male) and 4 or 5 (female) when stretched dorsally.

Tegument. Quite shiny. Stricture between prozona and metazona shallow, wide.

Metaterga (Fig. 18A-C). Metatergum 2 with 1(2)+1(2) anterior tubercles/cones and $2+2$ posterior spines; metatergum 3 with $1+1$ anterior tubercles (inconspicuous) and $2+2$ posterior spines; metaterga 4-19 with 2+2 posterior spines (anterior row absent; lateral spines of posterior row in all rings very long, longer than mesal ones).

Pleurosternal carinae. On body ring 2 long, crest-like; on body rings 3 and 4 small ridges; thereafter missing.

Paraterga (Figs 18F-G, 19B). Directed caudolaterad on body rings $2-18$, elevated at ca. $70^{\circ}$ (male) $60^{\circ}-70^{\circ}$ (female), directed increasingly caudad on body ring 19 ; notch near the tip at lateral margin of body rings $5-7,9,10,12,13,15-18$ absent on some rings in some specimens.

Telson (Fig. 19C-G). Epiproct quite short; tip usually subtruncate (in some specimens slightly emarginate); lateral setiferous tubercles conspicuous, long, digitiform; apical tubercles conspicuous. Hypoproct subtriangular; caudal margin subtriangular, with inconspicuous setiferous tubercles.

Sterna (Fig. 19H-J). Cross-impressions quite deep. Sternal lobe between male coxae 4 incompletely bilobed; base broad; tip deeply emarginate; surface near pores swollen.

Gonopods (Figs 4-5, 20-21). Coxa subequal in length to femur. Cannula long and slender. Telopodite quite long and slender. Prefemoral part ca. half as long as femur. Femur long and slender, slightly enlarged distally. Mesal sulcus conspicuous, deep, wide; lateral sulcus quite deep and very wide. Postfemoral part conspicuous, short. Solenophore well-developed: lamina lateralis long, lamellalike, thin, slender; tip round, directed ventrad: lamina medialis very long; slightly enlarged distally; apically fringed with several small spines; tip directed mesoventrad. Solenomere long and slender, tip directed ventrad.

\section{Distribution and habitat}

Nagaxytes gracilis gen. et sp. nov. is known only from Sai Yok District, Kanchanaburi Province. All specimens were collected on humid rocks, superficial tree roots and litter in limestone habitats. It lives in the same habitat with D. purpurosea, D. golovatchi Srisonchai, Enghoff \& Panha, 2018 and N. erecta gen. et sp. nov. (q.v.). The new species occurs in a narrow distribution area along the huge limestone range which is entirely contained within Sai Yok District. We thus consider this species to be endemic to Kanchanaburi Province, Thailand. 

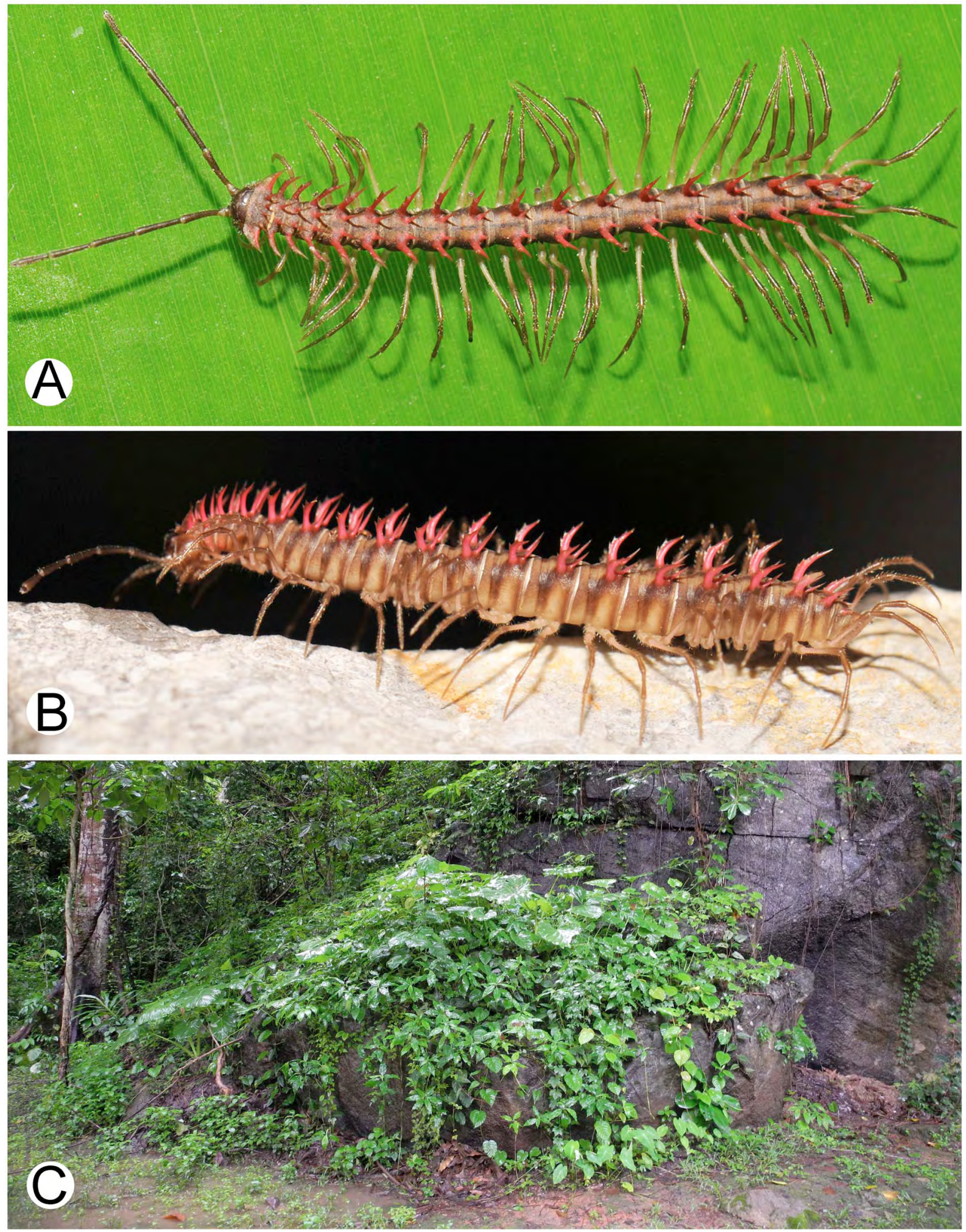

Fig. 17. Live photographs and habitat of Nagaxytes gracilis Srisonchai, Enghoff \& Panha gen. et sp. nov. (specimens from Daowadueng Cave, Thailand). A. $\mathcal{O}^{\lambda}$, paratype (CUMZ-pxDGT00091). B., , paratype (CUMZ-pxDGT00098). C. Habitat. 


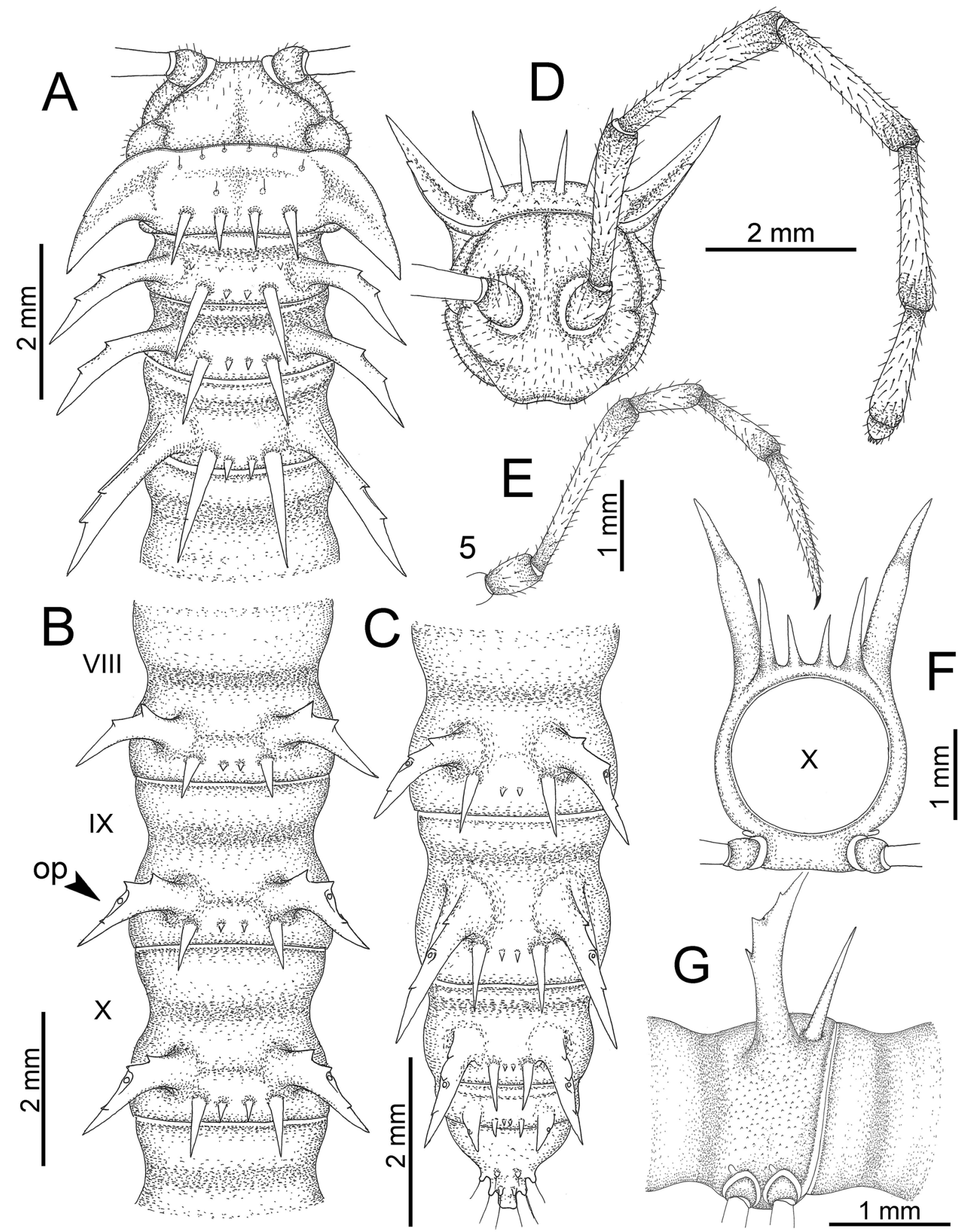

Fig. 18. Nagaxytes gracilis Srisonchai, Enghoff \& Panha gen. et sp. nov., $\hat{\jmath}$, paratype (CUMZpxDGT00091). A. Anterior body part. B. Body rings 8-10. C. Posteriormost body rings and telson. D. Head and antenna. E. $\widehat{\text { Oे }, ~ l e g ~} 5$ (right). F-G. Midbody ring. 


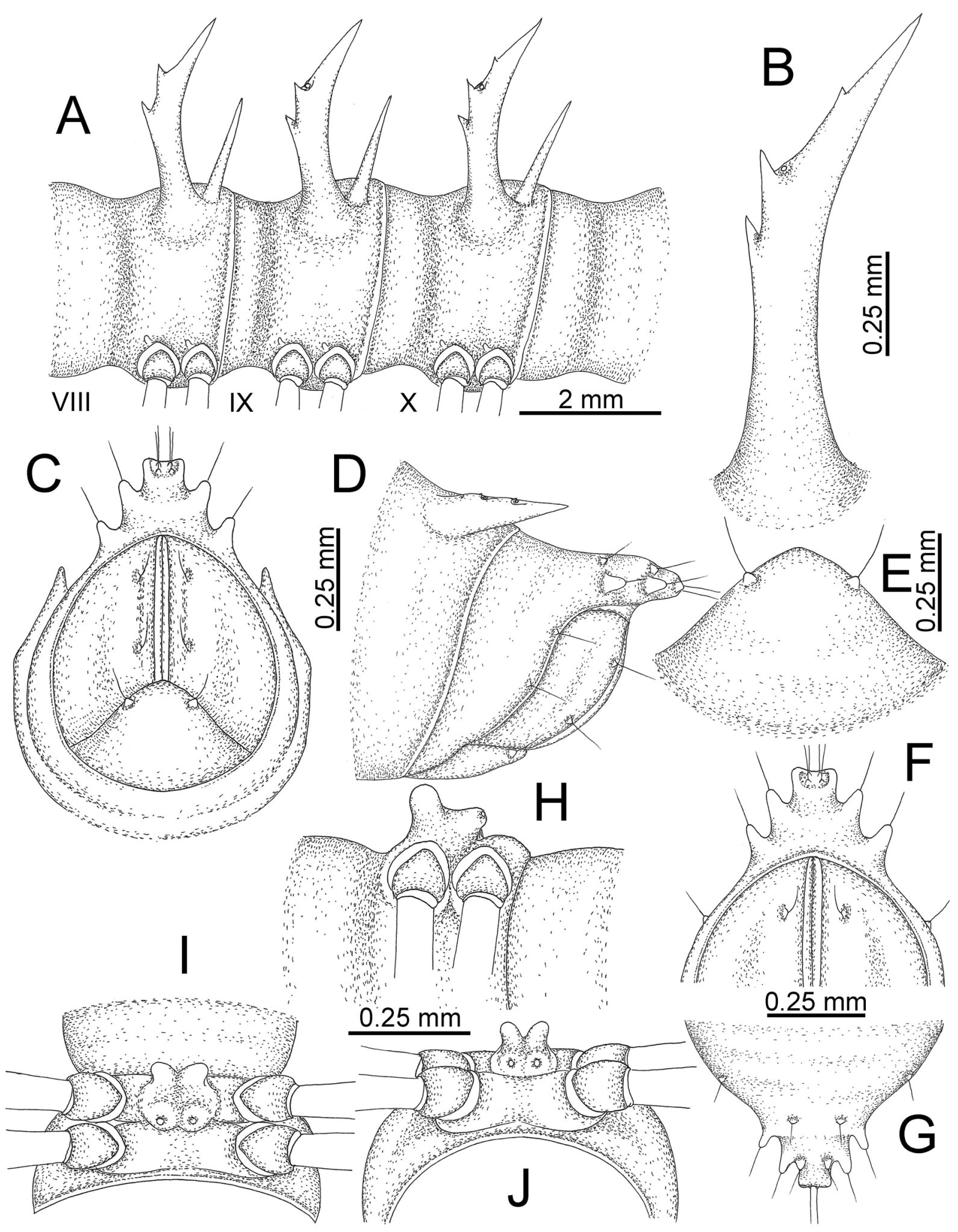

Fig. 19. Nagaxytes gracilis Srisonchai, Enghoff \& Panha gen. et sp. nov., $\hat{O}$, paratype (CUMZpxDGT00091). A. Body rings 8-10. B. Paraterga of ring 10. C-D. Last ring and telson. E. Hypoproct. F-G. Epiproct. H-J. Sternal lobe between coxae 4. 


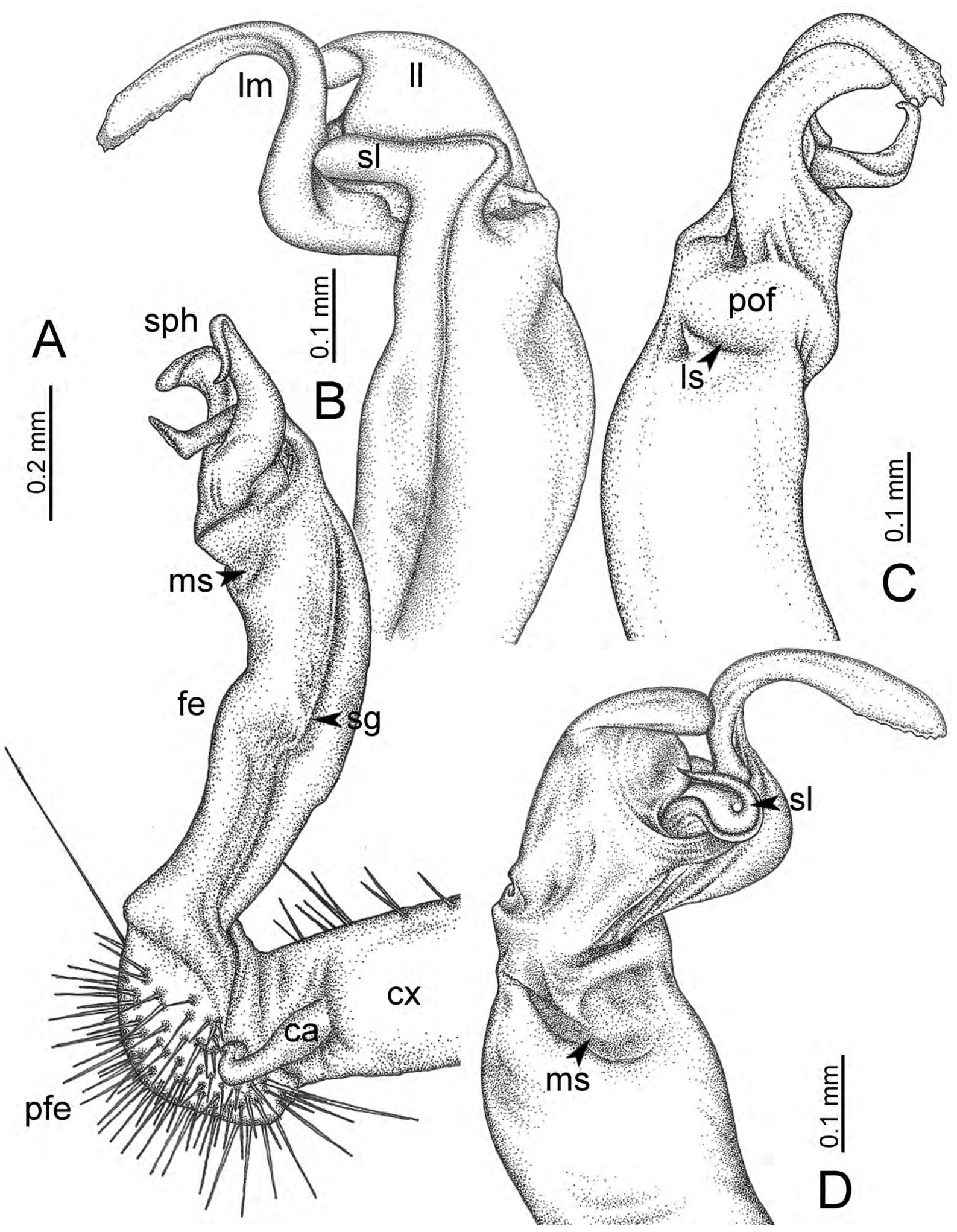

Fig. 20. Nagaxytes gracilis Srisonchai, Enghoff \& Panha gen. et sp.nov., paratype(CUMZ-pxDGT00092), right gonopod. A. Mesal view. B. Dorsal view. C. Lateral view. D. Ventral view. 


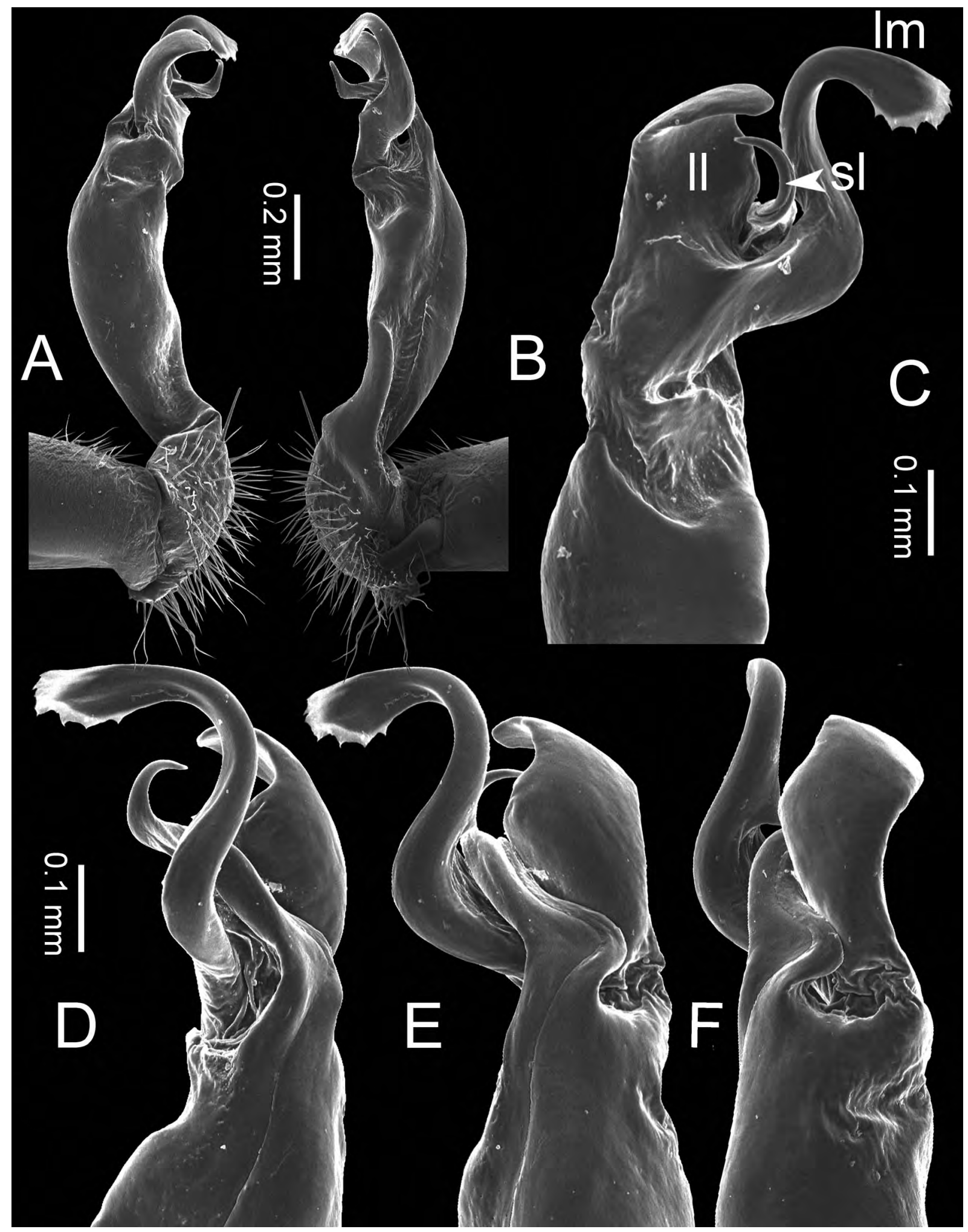

Fig. 21. Nagaxytes gracilis Srisonchai, Enghoff \& Panhagen. et sp. nov., paratype(CUMZ-pxDGT00092), right gonopod. A. Lateral view. B. Mesal view. C. Ventral view. D, F. Subdorsal view. E. Dorsal view. 


\section{Remarks}

The vivid pink paraterga are probably aposematic. Nagaxytes gracilis gen. et sp. nov. was noticeable in the field by the contrast of its bright pink colour to brown rocks.

There is a variability in the tip of the epiproct: in some specimens subtruncate, in others slightly emarginate.

Nagaxytes spatula Srisonchai, Enghoff \& Panha gen. et sp. nov. urn:1sid:zoobank.org:act:6B8E3EA4-8290-4EF4-A804-FCA28BE32863

Figs 22-26

\section{Diagnosis}

Metaterga 2-8 with two rows of spines ( $1+1$ or $2+2$ spines in anterior row, $2+2$ spines in posterior row). Similar in this respect to $N$. erecta gen. et sp. nov., but differs by having: degree of elevation of paraterga higher; apical tubercles of epiproct inconspicuous; surface near lateral sulcus swollen as long ridge; lamina lateralis broad, with a long and conspicuous spatula-like lobe; lamina medialis very long, curved, apically hook-like; tip of solenomere terminating in two curved processes.

\section{Etymology}

The name is a Latin noun in apposition, referring to the spatulate lobe on the lamina lateralis.

\section{Material examined}

\section{Holotype}

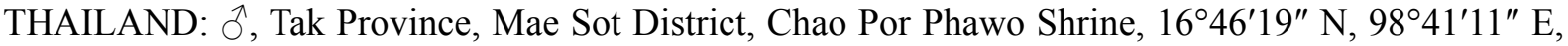
ca. 688 m a.s.1., 29 Aug. 2016, ASRU members leg. (CUMZ-pxDGT00119).

\section{Paratypes}

THAILAND: $27 \hat{\jmath} \hat{\partial}, 19 \uparrow$ 우, same data as for holotype (CUMZ-pxDGT00120-165); $1 \hat{\partial}, 1$ q, same data as for holotype (ZMUC 00040246); $1 \hat{\varnothing}, 1$, same data as for holotype (ZMUM); $1 \hat{\jmath}, 1$, same data as for holotype (NHMW); $1 \hat{\jmath}, 1$, same data as for holotype (NHMUK).

\section{Further specimens, not paratypes}

THAILAND - Tak Province: Mae Sot District: 1 q, Chao Por Phawo Shrine, 16 $46^{\prime} 19^{\prime \prime}$ N, 98 $41^{\prime} 11^{\prime \prime}$ E, ca. 688 m a.s.1., 29 Jun. 2015, ASRU members leg. (CUMZ); 1 ô, 1 क , Wat Tham Inthanin, $16^{\circ} 45^{\prime} 59^{\prime \prime} \mathrm{N}$, 98 40'21" E, $671 \mathrm{~m}$ a.s.1., 18 Oct. 2015, ASRU members leg. (CUMZ); 10 broken specs, Wat Pho

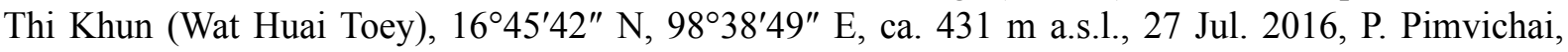
P. Prasankok and N. Nantarat leg. (CUMZ); 3 ऽิ $\hat{0}, 6$ 우, Wat Pho Thi Khun (Wat Huai Toey), $16^{\circ} 45^{\prime} 42^{\prime \prime}$ N, 98 $8^{\circ} 8^{\prime} 49^{\prime \prime}$ E, ca. 431 m a.s.1., 29 Aug. 2016, ASRU members leg. (CUMZ). - Umphang

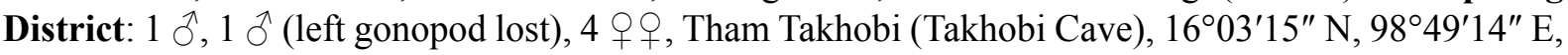
ca. $510 \mathrm{~m}$ a.s.1., 5 Jul. 2009, ASRU members leg. (CUMZ); 1 ${ }^{\lambda}, 1$ ㅇ, Tham Takhobi (Takhobi Cave),

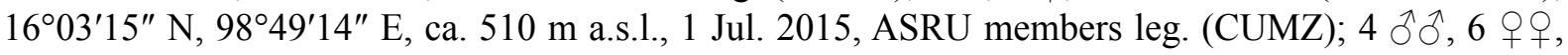

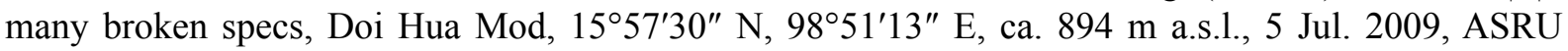

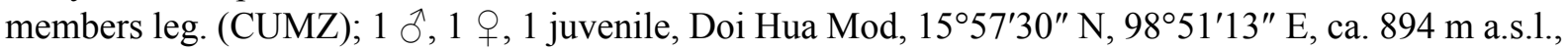
1 Jul. 2015, ASRU members leg. (CUMZ).

\section{Description}

SizE. Length 22-26 mm (male), 24-28 mm (female); width of midbody metazona ca. $2.0 \mathrm{~mm}$ (male), $2.8 \mathrm{~mm}$ (female). Width of head $<$ collum $=$ body ring $2=3=4<5-17$, thereafter body gradually tapering towards telson. 
Colour (Fig. 22A-C). Specimens in life with body usually reddish brown (some specimens brown); prozona, metaterga, surface below paraterga and sterna reddish brown; antennae brown to dark brown (except whitish distal part of antennomere 7 and antennomere 8); head, paraterga, epiproct and leg brown; a few basal podomeres pale brown. Colour in alcohol: after 3-10 years changed to pale brown; head, antennae, collum, metaterga, surface below paraterga, sterna, epiproct, legs pale brown or whitish brown; paraterga brownish white.

Collum (Fig. 23A). With three transverse rows of setiferous tubercles and spines, $3+3$ tubercles in anterior row, $1+1$ tubercles in intermediate row and $2+2$ spines in posterior row; paraterga of collum long and broad, elevated at ca. $25^{\circ}-35^{\circ}$ (male) $20^{\circ}-30^{\circ}$ (female), directed caudolaterad, with two conspicuous notches at lateral margin.

ANTENNAE (Fig. 23D). Very long and slender, reaching to body ring 6 or 7 (male) and 5 or 6 (female) when stretched dorsally.

Tegument. Quite dull. Stricture between prozona and metazona quite deep, wide.

Metaterga (Fig. 23A-C). Male - metaterga 2-8 with 2(1)+2(1) anterior spines and 2+2 posterior spines (anterior spines small and sometimes inconspicuous; posterior spines longer and larger than anterior ones; lateral spines of posterior row very long); metaterga 9-19 with ?1+?1 anterior small tubercles and $2+2$ posterior spines (lateral spines of posterior row very long). Female - metaterga 2-10 with $2+2$ anterior spines and $2+2$ posterior spines (posterior spines longer and larger than anterior ones; lateral spines of posterior row very long); metaterga 11-18 with $1+1$ anterior spines and $2+2$ posterior spines (lateral spines of posterior row very long); metatergum 19 with ?1+?1 anterior small tubercles and $2+2$ posterior spines.

Pleurosternal carinae. On body ring 2 long, crest-like; on ring 3 long ridges; on ring 4 small ridges; thereafter missing.

Paraterga (Figs 23F-G, 24B). Directed caudolaterad on body rings $2-18$, elevated at ca. $50^{\circ}-60^{\circ}$ (male) $45^{\circ}-50^{\circ}$ (female), directed increasingly caudad on body ring 19 .

Telson (Fig. 24C-G). Epiproct quite short; tip subtruncate; lateral setiferous tubercles conspicuous, long, digitiform; apical tubercles inconspicuous. Hypoproct subtriangular, short and broad; caudal margin round, with conspicuous setiferous tubercles.

Sterna (Fig. 24H-J). Cross-impressions shallow. Sternal lobe between male coxae 4 stout; base broad; tip deeply emarginate to incompletely bilobed.

Gonopods (Figs 25, 26). Coxa shorter than femur. Cannula quite short and stout. Telopodite quite short and stout. Prefemoral part subequal in length to femur. Femur quite stout, slightly enlarged distad. Mesal sulcus conspicuous, deep, wide; lateral sulcus quite shallow and wide, surface near lateral sulcus swollen as long ridge. Postfemoral part conspicuous, wide, laterally demarcated from femur by a long ridge. Solenophore well-developed: lamina lateralis broad; with a long, flattened, conspicuous spatulate lobe, apically round, directed anteriad (Figs 25D, 26C); lamina medialis very long; curved; apically hooklike. Solenomere long, tip terminating in two curved processes.

\section{Distribution and habitat}

Known only from Tak Province. Almost all specimens were seen crawling on rocks, some on leaf litter in limestone habitats. Some juveniles were collected from the leaf litter (probably in moulting chambers). In the field, the specimens blended perfectly with brown rocks and leaf litter. 

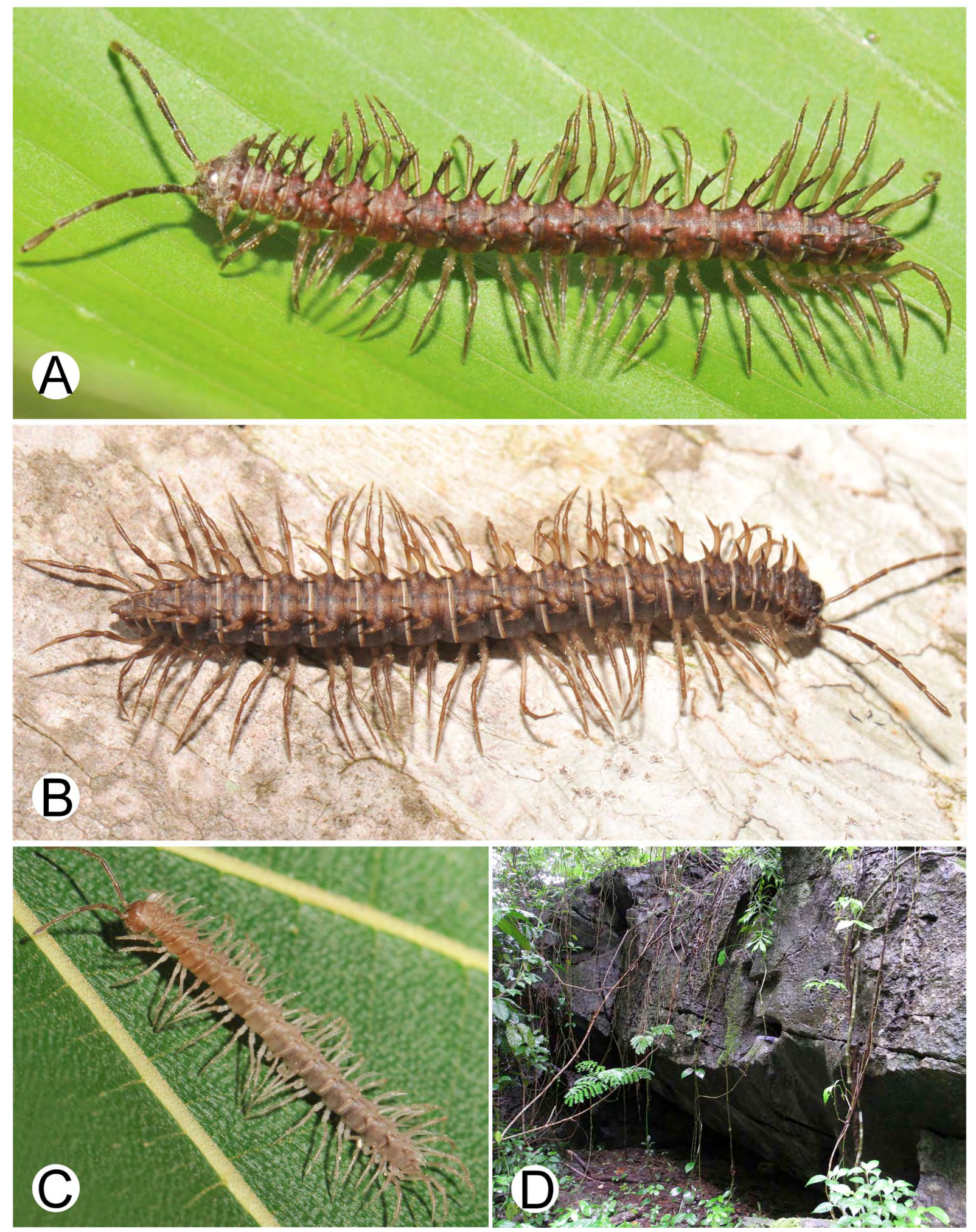

Fig. 22. Live photographs and habitat of Nagaxytes spatula Srisonchai, Enghoff \& Panha gen. et sp. nov. (specimens from Chao Por Phawo Shrine, Thailand). A. $\hat{\jmath}$, paratype (CUMZ-pxDGT00120). B. + , paratype (CUMZ-pxDGT00147). C. ̊̊, paratype (CUMZ-pxDGT00146), newly moulted adult. D. Habitat. 


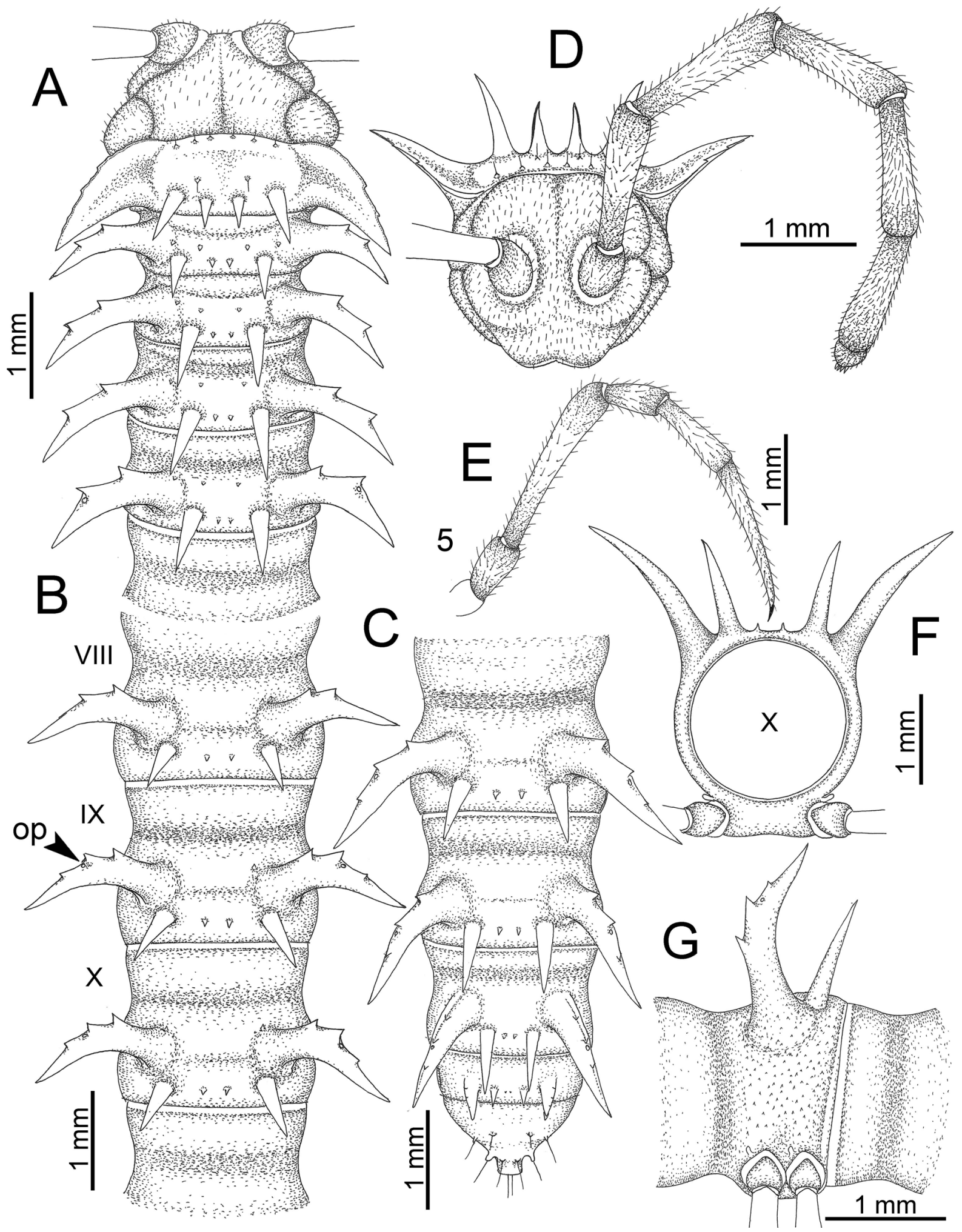

Fig. 23. Nagaxytes spatula Srisonchai, Enghoff \& Panha gen. et sp. nov., $\hat{\partial}$, paratype (CUMZpxDGT00120). A. Anterior body part. B. Body rings 8-10. C. Posteriormost body rings and telson. D. Head and antenna. E. Ô, leg 5 (right). F-G. Midbody ring. 


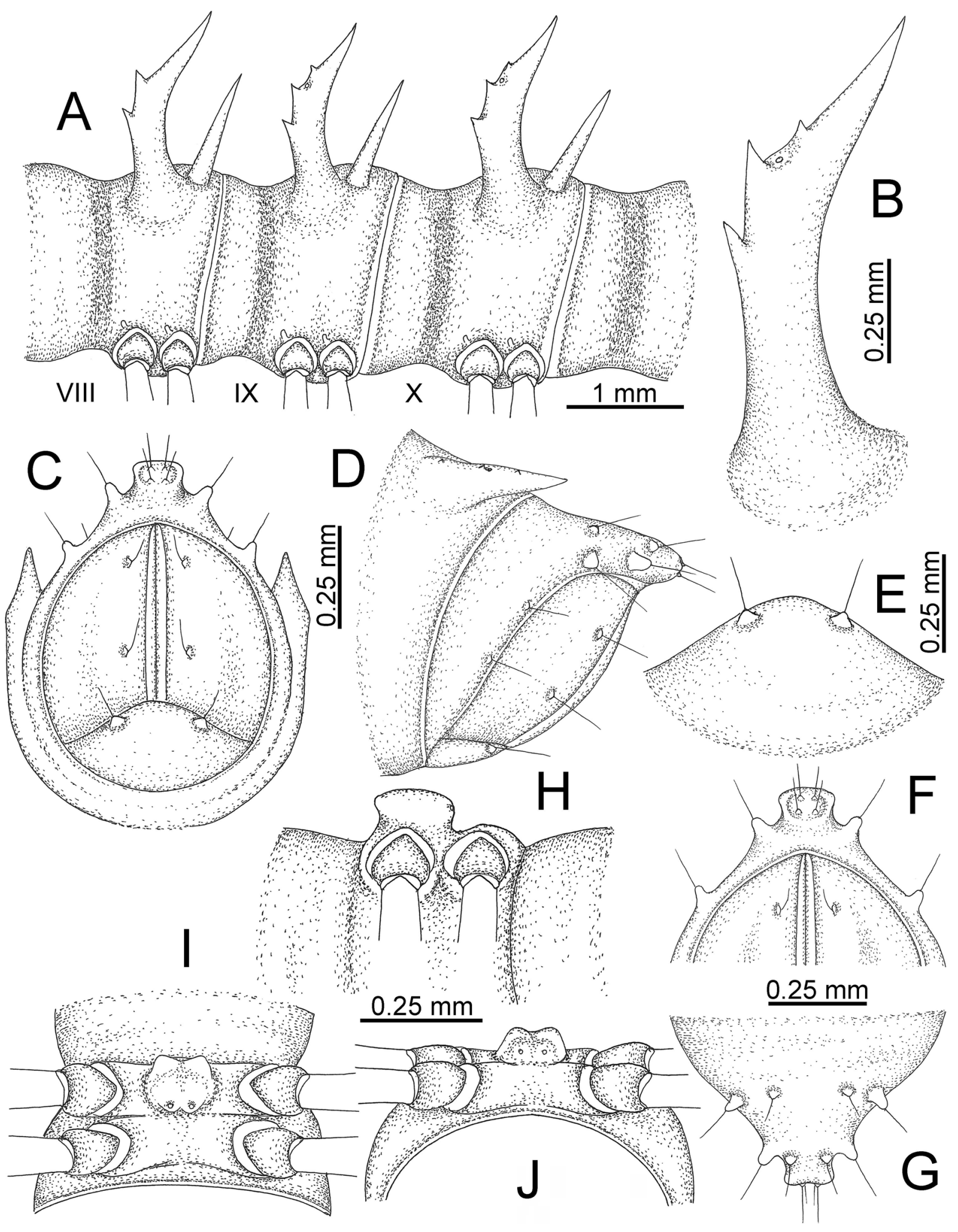

Fig. 24. Nagaxytes spatula Srisonchai, Enghoff \& Panha gen. et sp. nov., $\hat{\jmath}$, paratype (CUMZpxDGT00120). A. Body rings 8-10. B. Paraterga of ring 10. C-D. Last ring and telson. E. Hypoproct. F-G. Epiproct. H-J. Sternal lobe between coxae 4. 


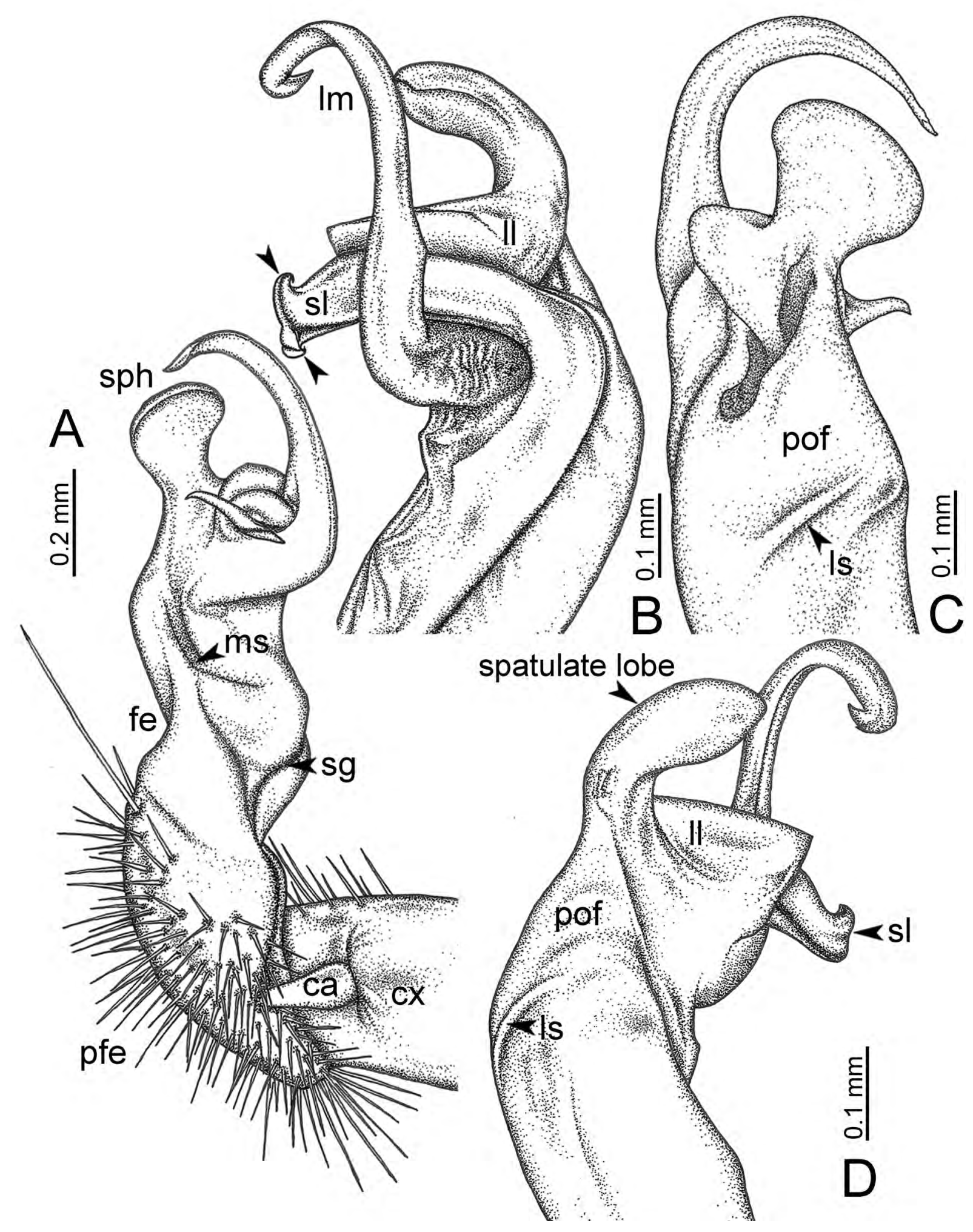

Fig. 25. Nagaxytes spatula Srisonchai, Enghoff \& Panha gen. et sp. nov., paratype (CUMZ-pxDGT00121), right gonopod. A. Mesal view. B. Dorsal view (arrowheads = tip of solenomere terminating in two curved processes). C. Lateral view. D. Ventral view. 


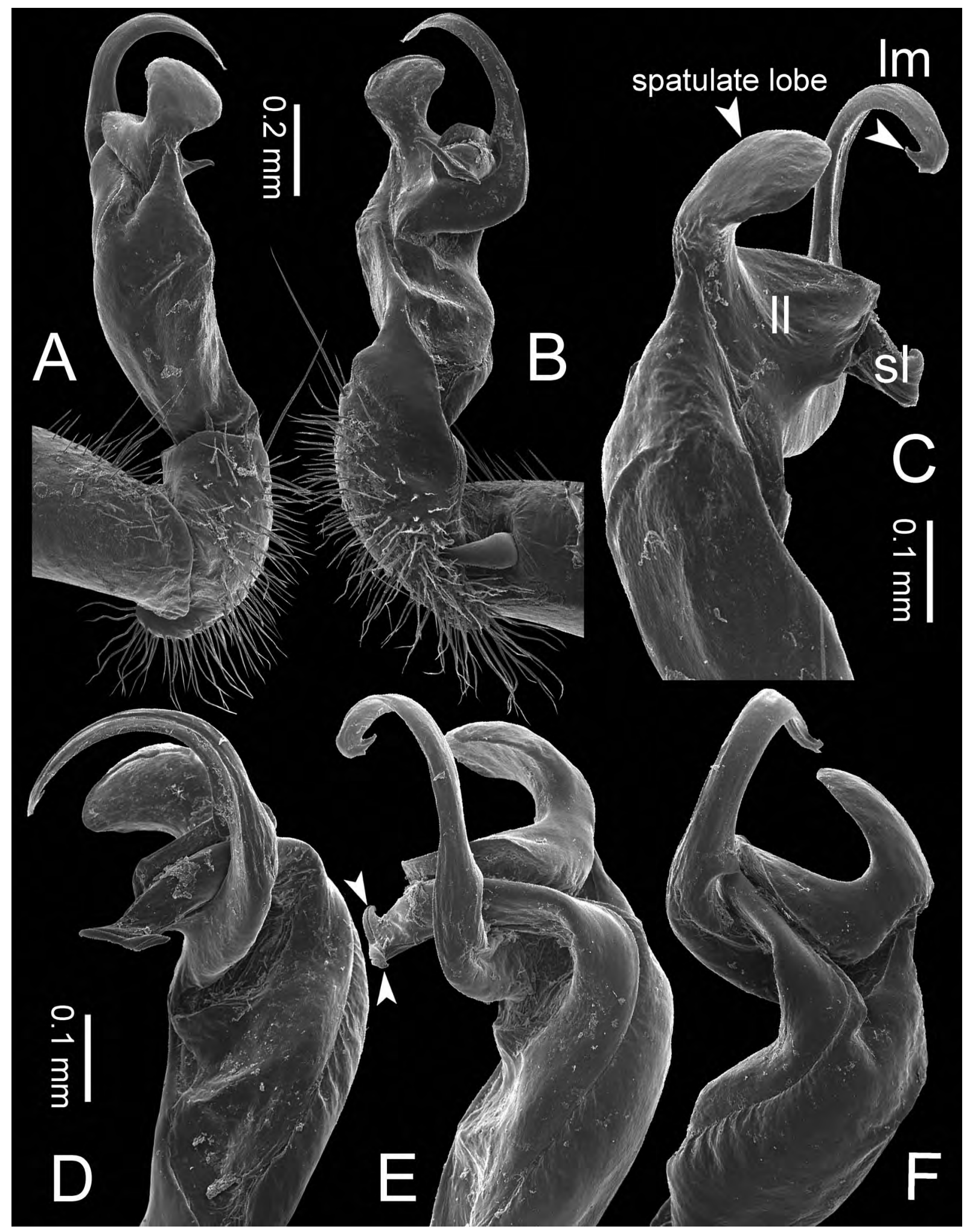

Fig. 26. Nagaxytes spatula Srisonchai, Enghoff \& Panha gen. et sp. nov., paratype (CUMZpxDGT00121), right gonopod. A. Lateral view. B. Mesal view. C. Ventral view (arrowhead = hook-like tip). D, F. Subdorsal view. E. Dorsal view (arrowheads = tip of solenomere terminating in two curved processes). 
The type locality for this species is situated beside road no. 12 (Tak-Mae Sot) near Khun Phawo National Park. We noticed that the forest beside the road is being destroyed for road construction, some parts of the limestone forest are being cut down.

For the time being, only five recorded locations are reported in the quite narrow distribution range of this species. After several intensive surveys we consider $N$. spatula gen. et sp. nov. to be endemic to Tak Province, Thailand.

\section{Remarks}

We divide this species into two main populations, each restricted to a separate limestone areas:

- North populations: Chao Por Phawo Shrine, Wat Tham Inthanin and Wat Pho Thi Khun (Wat Huai Toey).

- South populations: Tham Takhobi (Takhobi Cave) and Doi Hua Mod.

Specimens of the North populations (24-26 mm in male, $26-28 \mathrm{~mm}$ in female) seem to be longer than those of the South populations (22-24 mm in male, 24-25 mm in female). However, other morphological characteristics, especially gonopod characters, are identical.

\section{Discussion}

On the basis of our morphological study and a preliminary DNA sequence analysis (work in progress), the 'acantherpestes' group as defined by Srisonchai et al. (2018) is here described as a new genus which includes 'Desmoxytes' acantherpestes and three new species. The new genus Nagaxytes gen. nov. is well-characterised by having subspiniform paraterga, unmodified male femora, as well as a curved and long lamina medialis. Each of the four species can be easily distinguished from its congeners by distinctive gonopod characters, especially the shape of the lamina lateralis in combination with other morphological characters.

Nagaxytes erecta gen. et sp. nov. includes two colour morphs: brownish red and brown. Moreover, the size of tubercles/cones/spines (anterior row) on metaterga 16-19 also differs between the two colour morphs: anterior row of tubercles/cones/spines conspicuous in the brownish red morph, inconspicuous in the brown morph. However, other morphological characters are clearly identical, especially gonopod characters: lamina lateralis long, thick, digitiform (Figs 14, 17). Interestingly, the two morphs mainly occur allopatrically, although at Daowadueng Cave and Wat Sunantha Wanaram, they were found syntopically in the same habitat. This case is similar to that of Desmoxytes cervina: similarity in several morphological characters, but differences in colour between two allopatric and/or sympatric populations (Srisonchai et al. 2018). We hope that our molecular phylogeny work combined with morphological studies will shed more light on relationships within populations, within species, within the genus Nagaxytes gen. nov., as well as among its closely related genera.

Nagaxytes erecta gen. et sp. nov. has been found in partial sympatry with $N$. gracilis gen. et sp. nov. at Daowadueng Cave and Wat Sunantha Wanaram in Kanchanaburi Province. Both species show a similar pattern of gonopod shape and share a long lamina lateralis (e.g., Figs 15D, 21D), yet they are not identical. The differences in shape of the sternal lobe between male coxae 4 and the pattern of row of spines on metaterga support regarding them as different taxa. Although $N$. erecta gen. et sp. nov. and $N$. gracilis gen. et sp. nov. have been found to be syntopic, even collected from the same habitat, the details of their microhabitats have not yet been observed and they may not co-occur in a strict sense. 


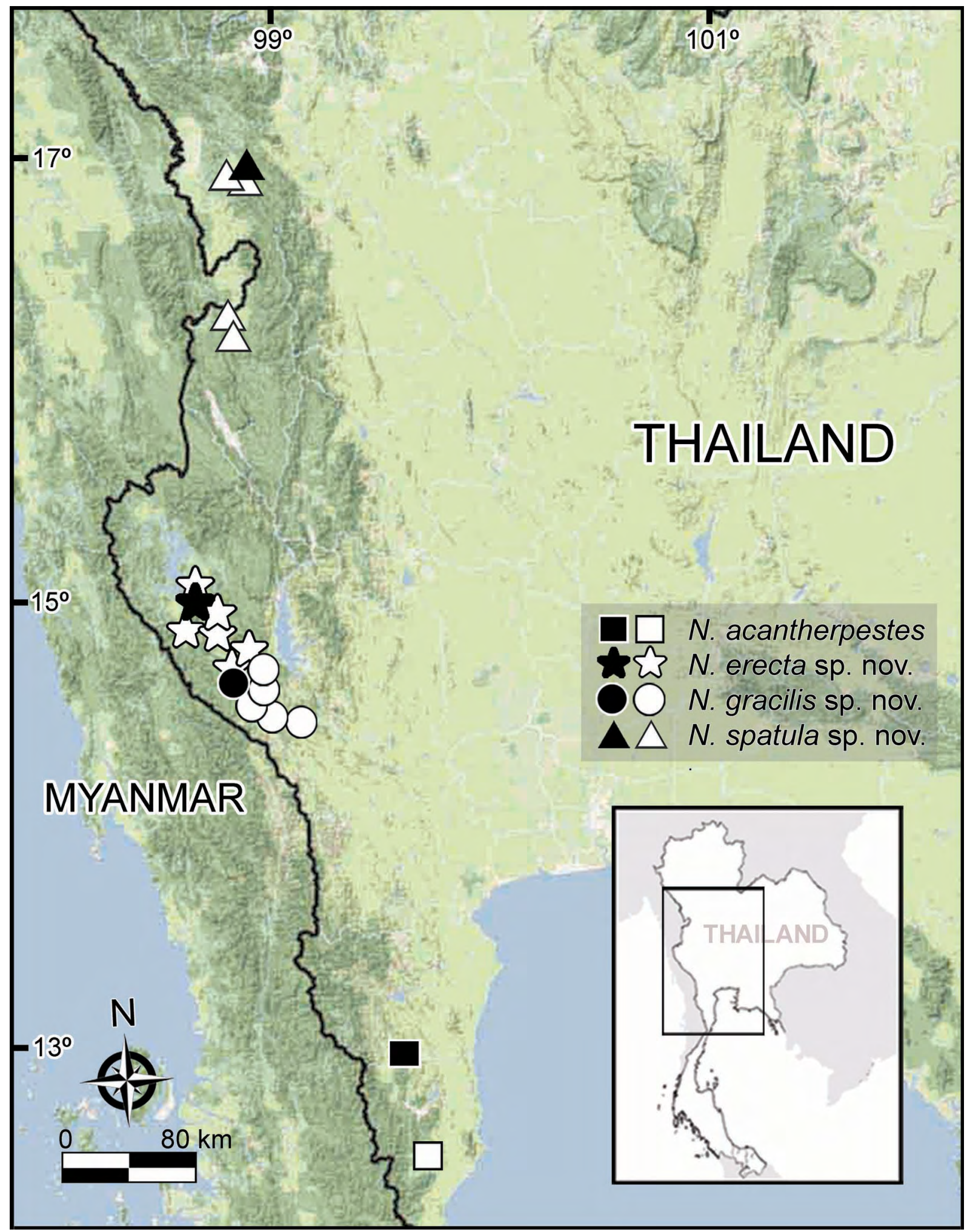

Fig. 27. Known distribution of all species of Nagaxytes Srisonchai, Enghoff \& Panha gen. nov. (black symbol = type locality, white symbol $=$ other localities). 
During the field surveys, we found associations of mites with two species of Nagaxytes gen. nov.: $N$. acantherpestes gen. et comb. nov. and $N$. erecta gen. et sp. nov. The mites probably belong to the genus Leptus Latreille, 1796 (Southcott 1992). As in the association between parasitic mites and millipedes of the genus Desmoxytes reported by Srisonchai et al. (2018), it seems likely that the mites use their hosts for nourishment and dispersal purposes, as in other mite-millipede associations (Kethley 1978; Swafford \& Bond 2010).

The new species described here are further examples of the peculiar dragon millipedes. Their long subspiniform paraterga may provide protection against predators and possibly enhance the spreading of their defense fluid (Shear 2015; Liu et al. 2017). In addition, one of the new species, $N$. gracilis gen. et sp. nov., is spectacularly aposematic, like several dragon millipedes in the genus Desmoxytes (Enghoff et al. 2007; Srisonchai et al. 2018).

Based on our surveys and observations, all species of Nagaxytes gen. nov. have narrow distribution ranges within limestone habitats (Fig. 27). Therefore, we regard all species of Nagaxytes gen. nov. as endemic to the Thai fauna. We would not be surprised if so far unsurveyed limestone areas will yield more new species of this peculiar genus.

\section{Acknowledgements}

This research was funded by a grant from the Thailand Research Fund, the TRF Senior Research Scholar (2015-2018), RTA 5880002 to SP and from center of excellence on Biodiversity (BDC-PG2-160011). RS's visit for one year to the Natural History Museum of Denmark, University of Copenhagen, was supported by a grant from Human Resource Development in Science Project (Science Achievement Scholarship of Thailand (SAST)) and an internal grant from the Natural History Museum of Denmark. We are particularly grateful to the Plant Genetic Conservation Project under the Initiative of Her Royal Highness Maha Chakri Sirindhorn and Center of Excellence on Biodiversity for permission and support in access, and for enabling field trips to several restricted/remote areas. This work would not have been possible at all without the impressive collections and great encouragements made by members of Animal Systematic Research Unit (ASRU). Our sincere thanks are due to the reviewers including S. I. Golovatch for their comments and valuable advice. Special thanks go to Ms T. Krutchen for teaching the drawing skills and P. Kriatpraprai for the watercolour.

\section{References}

Decker P. 2010. Contributions to the myriapod fauna of Thailand - New records of millipedes and centipedes from Thailand (Myriapoda: Diplopoda, Chilopoda). Schubartiana 4: 23-34. Available from http://schubartiana.de/issues/pdf/vol4/Decker-2010-Myriapod_fauna_of_Thailand.pdf [accessed 22 Aug. 2018].

Enghoff H. 2005. The millipedes of Thailand (Diplopoda). Steenstrupia 29 (1): 87-103. Available from http://www.zmuc.dk/commonweb/JOURNALS/PDF/Vol29-1/Enghoff.pdf [accessed 22 Aug. 2018].

Enghoff H., Sutcharit C. \& Panha S. 2007. The shocking pink dragon millipede, Desmoxytes purpurosea, a colourful new species from Thailand (Diplopoda: Polydesmida: Paradoxosomatidae). Zootaxa 1563: 31-36.

Golovatch S.I. \& Enghoff H. 1994. Review of the dragon millipedes, genus Desmoxytes Chamberlin, 1923 (Diplopoda, Polydesmida, Paradoxosomatidae). Steenstrupia 20 (2): 45-71.

Jeekel C.A.W. 1964. Two new species of Pratinus Attems, with taxonomic notes on the genus and a redescription of its type-species (Diplopoda, Polydesmida). Beaufortia 11 (137): 61-73. Available from http://www.repository.naturalis.n1/document/548475 [accessed 22 Aug. 2018]. 
Jeekel C.A.W. 1980. The generic allocation of some little-known Paradoxosomatidae from SouthEast Asia (Diplopoda, Polydesmida). Revue suisse de Zoologie 87 (3): 651-670. Available from https://biodiversitylibrary.org/page/41420961 [accessed 22 Aug. 2018].

Jeekel C.A.W.2003. African Paradoxosomatidae, 1: Genus Eviulisoma Silvestri(Diplopoda, Polydesmida). Myriapod Memoranda 6: 46-88.

Kethley J.B. 1978. Narceolaelaps n. g. (Acari: Laelapidae) with four new species parasitizing spiroboloid millipedes. International Journal of Acarology 4: 195-210. https://doi.org/10.1080/01647957808683117

Liu W., Golovatch S., Wesener T. \& Tian M. 2017. Convergent evolution of unique morphological adaptations to a subterranean environment in cave millipedes (Diplopoda). PLoS ONE 12 (2): e0170717. https://doi.org/10.1371/journal.pone.0170717

Nguyen D.A. \& Sierwald P. 2013. A worldwide catalog of the family Paradoxosomatidae Daday, 1889 (Diplopoda: Polydesmida). Check List 9 (6): 1132-1353. https://doi.org/10.15560/9.6.1132

Shear W.A. 2015. The chemical defenses of millipedes (Diplopoda): Biochemistry, physiology and ecology. Biochemical Systematics and Ecology 61: 78-117. https://doi.org/10.1016/j.bse.2015.04.033

Southcott R.V. 1992. Revision of the larvae of Leptus Latreille (Acarina: Erythraeidae) of Europe and North America, with descriptions of post-larval instars. Zoological Journal of the Linnean Society 105 (1): 1-153. https://doi.org/10.1111/j.1096-3642.1992.tb01228.x

Srisonchai R., Enghoff H., Likhitrakarn N. \& Panha S. 2016. Four colorful new species of dragon millipedes, genus Desmoxytes Chamberlin, 1923, from northern Thailand (Diplopoda: Polydesmida: Paradoxosomatidae). Zootaxa 4710 (1): 93-113. https://doi.org/10.11646/zootaxa.4170.1.4

Srisonchai R., Enghoff H., Likhitrakarn N. \& Panha S. 2018. A revision of dragon millipedes I: genus Desmoxytes Chamberlin, 1923, with the description of eight new species (Diplopoda, Polydesmida, Paradoxosomatidae). ZooKeys 761: 1-177. https://doi.org/10.3897/zookeys.761.24214

Swafford L. \& Bond J.E. 2010. Failure to cospeciate: an unsorted tale of millipedes and mites. Biological Journal of the Linnean Society 101 (2): 272-287. https://doi.org/10.1111/j.1095-8312.2010.01499.x

Manuscript received: 25 April 2018

Manuscript accepted: 16 July 2018

Published on: 25 September 2018

Topic editor: Rudy Jocqué

Desk editor: Pepe Fernández

Printed versions of all papers are also deposited in the libraries of the institutes that are members of the EJT consortium: Muséum national d'Histoire naturelle, Paris, France; Botanic Garden Meise, Belgium; Royal Museum for Central Africa, Tervuren, Belgium; Natural History Museum, London, United Kingdom; Royal Belgian Institute of Natural Sciences, Brussels, Belgium; Natural History Museum of Denmark, Copenhagen, Denmark; Naturalis Biodiversity Center, Leiden, the Netherlands; Museo Nacional de Ciencias Naturales-CSIC, Madrid, Spain; Real Jardín Botánico de Madrid CSIC, Spain; Zoological Research Museum Alexander Koenig, Bonn, Germany. 